FEDERAL

RESERVE

BANK of

ST. LOUIS
RESEARCH DIVISION

Working Paper Series

\title{
Two-Way Capital Flows and Global Imbalances
}

\author{
Pengfei Wang, \\ Yi Wen \\ and \\ Zhiwei Xu
}

\author{
Working Paper 2012-016B \\ https://doi.org/10.20955/wp.2012.016
}

March 2015

\section{FEDERAL RESERVE BANK OF ST. LOUIS}

Research Division

P.O. Box 442

St. Louis, MO 63166

The views expressed are those of the individual authors and do not necessarily reflect official positions of the Federal Reserve Bank of St. Louis, the Federal Reserve System, or the Board of Governors.

Federal Reserve Bank of St. Louis Working Papers are preliminary materials circulated to stimulate discussion and critical comment. References in publications to Federal Reserve Bank of St. Louis Working Papers (other than an acknowledgment that the writer has had access to unpublished material) should be cleared with the author or authors. 


\title{
Two-Way Capital Flows and Global Imbalances*
}

\author{
Pengfei Wang, ${ }^{a}$ Yi Wen, ${ }^{b, c}$ and Zhiwei $\mathbf{X u}^{d}$
}

(This version: February 2015)

\begin{abstract}
Financial capital and fixed capital tend to flow in opposite directions between poor and rich countries. This paper introduces frictions into a standard two-country neoclassical growth model to explain the pattern of two-way capital flows between emerging economies (such as China) and the developed world (such as the United States). We show how underdeveloped financial markets in China can lead to abnormally high rates of return to fixed capital but excessively low rates of return to financial capital relative to the U.S., hence driving out household savings (financial capital) on the one hand while simultaneously attracting foreign direct investment (FDI) on the other. When calibrated to match China's high marginal product of capital and low real interest rate, our model is able to account for China's rising financial capital outflows and FDI inflows as well as its massive trade imbalances in the past decades. Our model yields two additional implications that stand in sharp contrast to the existing literature: (i) Global trade imbalances between emerging economies and the developed world may be sustainable even in the long run; and (ii) the conventional wisdom that the "saving glut" of emerging economies is responsible for the global low world interest rate may be wrong.
\end{abstract}

Keywords: Allocation Puzzle, Saving Glut, FDI, Global Imbalances, Two-Way Capital Flows, China.

JEL Classification: E21, E22, E44, F21, F32, F34, F41.

${ }^{*}$ We thank Yili Chien, Kaiji Chen, Bill Gavin, Jiandong Ju, Qing Liu, B. Ravikumar, Tao Zha and seminar participants at Emory University, HKUST, Tsinghua University, Federal Reserve Bank of St. Louis, Shanghai Jiao Tong University, Columbia-Tsinghua Conference in International Economics and SED 2013 Annual meeting for comments, and Judy Ahlers for editorial assistance. Pengfei Wang acknowledges the financial support from Hong Kong Research Grants Council (project \#643912). Zhiwei Xu acknowledges the financial support from National Natural Science Foundation of China (No. 71403166). The usual disclaimer applies. a: Hong Kong University of Science \& Technology. $b$ : Federal Reserve Bank of St. Louis. $c$ : Tsinghua University. $d$ : Shanghai Jiao Tong University. 


\section{Introduction}

The pattern of international capital flows is a long-standing puzzle. Lucas (1990) ponder why capital does not flow from North (developed countries) to South (developing countries) even though it is scarcer and commands a higher rate of return (or marginal product) in the latter. The standard neoclassical growth theory attributes the high marginal product of capital (MPK) in the South to low household savings, thus predicting a capital flow from rich to poor countries. But in fact savings abound in many emerging economies and massive amount of capital have been flowing into rich countries over the past decades.

To explain the "reverse" capital flow puzzle, the mainstream literature on global imbalances argues that the rate of return to capital is actually lower (rather than higher) in developing economies because of a savings glut (Bernanke, 2005). Hence, capital moves in the reverse direction-from South to North.

However, the reverse capital flow puzzle is partially a fallacy of aggregation. In reality, fixed capital does flow mainly from North to South, in the form of foreign direct investment (FDI). It is financial capital (portfolio investment) that has been flowing in the opposite direction. Since historically the "uphill" flows of financial capital dominate the "downhill" flows of fixed capital, the net aggregate capital flow (financial plus fixed) shows the reverse pattern.

For example, during the 2000-2011 period, industrial countries as a whole had net financial capital inflows (including foreign reserve decumulations) averaging $-\$ 498$ billion per year and net FDI outflows averaging $\$ 295$ billion per year. In contrast, the less developed countries (LDCs) as a block had net FDI inflows averaging $-\$ 246$ billion per year and net financial capital outflows (including foreign reserve accumulations) averaging $\$ 354$ billion per year. These opposite movements (or diverging trends) in financial and fixed capital flows have been growing over time. ${ }^{1}$ In the meantime, industrial countries have been running large and persistent trade deficits with the South. The major countries contributing to such global imbalances are the U.S. (representing developed countries) and China (representing LDCs in recent years). In particular, China is now both the largest holder of foreign reserves (more than $\$ 3$ trillion by the end of 2011, mostly U.S. government bonds) and the largest recipient of FDI (more than $\$ 1.4$ trillion by the end of 2011) among developing countries, as well as the main contributor to global current account imbalances (e.g., with average surplus of over $\$ 250$ billion per year in the $2005-2011$ period). In contrast, the U.S. is the largest importer of financial capital from developing countries and the largest exporter of FDI to the South. Meanwhile, the U.S. is also the country with the largest trade deficit (e.g., with average current account deficit of over $\$ 600$ billion per year in the 2005 -2011 period).

\footnotetext{
${ }^{1}$ These statistics were updated from Lane and Milesi-Ferretti (2007).
} 
Despite the importance of FDI in North-South trade and its growing significance in rebalancing international capital flows and national current accounts, the bulk of the existing literature on global imbalances does not distinguish financial capital from fixed capital flows. Failing to distinguish these two forms of capital flows not only obscures the reality but may also impede correct theoretical analysis and empirical testing with different models aimed at explaining capital flows and the associated global imbalances.

This paper provides a framework to explain the two-way capital flow puzzle by augmenting the neoclassical growth model with financial frictions under incomplete markets. Specifically, following the approach of Gourinchas and Jeanne (2013), we augment the neoclassical growth model with two wedges: one that distorts firms' investment decisions and another that distorts households' saving decisions. However, unlike in Gourinchas and Jeanne's (2013) approach where the wedges are ad hoc black boxes, in our approach these wedges are explicitly derived through financial frictions, thus providing micro foundations for these theoretical constructs.

Our story proceeds as follows. Due to an underdeveloped banking-credit-financial system, both households and firms in the South are severely borrowing constrained. As a result, households opt to save excessively to self-insure against unpredictable shocks, and firms have to rely heavily on internal cash flows to finance fixed investment. Since domestic savings by households cannot be effectively channeled to firms where fixed capital formation takes place, fixed capital is scarce in the production sector while savings are abundant in the household sector. In such a world, the rate of return to financial assets can be significantly lower than that of fixed capital. In China, for example, the real rate of return to fixed capital has consistently been over $20 \%$ in the past decades while the real rate of return to financial capital (such as bank deposits and short-term bonds) has been negative (Bai, Hsieh, and Qian, 2006). Despite such an enormous gap, households in China save excessively and the bulk of their savings is in the form of bank deposits (Wen, 2009, 2011). This enormous arbitrage opportunity implies that financial liberalization between the South and the North will trigger two-way capital flows. Because it is relatively easier for financial capital to flow internationally than for fixed capital to be shipped abroad (e.g., due to transaction and transportation costs), the former will dominate the latter in global capital flows, resulting in shortrun current account imbalances. In addition, because the rates of return to fixed and financial capital differ, the net income (interest) payments on the opposite capital flows do not cancel out, further contributing to global trade imbalances even in the long run.

Therefore, in contrast to the standard neoclassical theory which attributes high MPK in the South to low household savings, we show how the lack of an efficient financial system in the South can lead to insufficient investment on the firm side but a saving glut on the household side, resulting in a high MPK and a low interest rate at the same time. These wedges in rates of return drive the observed two-way capital flows between developing and developed countries and the current account 
imbalances. More importantly, we show that such two-way capital flows can sustain permanent trade imbalances even if the current account is perfectly balanced at zero. ${ }^{2}$

Our analysis is related to a large and growing literature on global imbalances. Ju and Wei (2010) study two-way capital flows in a static non-neoclassical model with a focus on corporate governance and property rights. Caballero et al. (2008) attribute the global imbalances to the South's inability to generate saving instruments, leading to the reverse capital flow after financial liberalization. Mendoza, Quadrini and Rois-Rull (MQR, 2009) blame the global imbalances on the heterogeneous degrees of financial development between developed and developing countries. Such heterogeneity implies that households in the North prefer riskier equity in their portfolios than do households in the South, causing the South to maintain a positive net asset position in risk-free bonds. Similar to MQR (2009), Angeletos and Panousi (2011) ascribe global imbalances to heterogeneous degrees of idiosyncratic risks between the North and the South. Outflows of financial capital from the South are driven by its low interest rate under the precautionary saving motives. Like us, Angeletos and Panousi allow firms to accumulate fixed capital and their model can also generate a wedge between the MPK and the real interest rate. In contrast to our study, however, theirs does not consider FDI and two-way capital flows. Related works also include Ohanian and Wright (2007), Sandri (2010), Carroll and Jeanne (2009), Durdu, Mendoza, and Terrones (2009), Buera and Shin (2010), Chien and Naknoi (2011), Song, Storesletten, and Zilibotti (2011), Gourinchas and Jeanne (2013), Andolfatto (2012), and Wen (2009, 2011), among many others. ${ }^{3}$

However, the bulk of this literature does not distinguish between financial capital and fixed capital flows. ${ }^{4}$ As such, many of the models that are proposed to explain the global imbalances are simply inconsistent with the empirical pattern of the two-way capital flows and trade imbalances. Typically, because no distinction is made between household savings and firms' fixed capital stocks, to explain the reverse capital flow such a model would imply excess domestic savings in the form of tangible capital goods, which are rented out to foreign firms as a form of capital outflows (e.g., Carroll and Jeanne, 2009). This particular form of capital outflows from the South to the North is inconsistent with the empirical facts. ${ }^{5}$

The work closest to ours is MQR (2009). Our approach complements that of MQR in several aspects. In contrast to our full-fledged DSGE model, MQR's model assumes that the stock of

\footnotetext{
${ }^{2}$ That is, imbalanced trade exists even if financial capital flows and fixed capital flows exactly cancel (balance) each other-because the cross-country net factor payments do not necessarily cancel each other due to the investment wedge.

${ }^{3}$ This literature does not address the main issues raised by Wen (2011), especially the positive relationship between China's high saving rate and rapid income growth rate and the connection between capital controls and trade.

${ }^{4}$ Even in the model of Ju and Wei (2010), there is only one form of capital that flows in and out to form a two-way flow circle. For example, it flows out to by-pass domestic regulations and then flows back. Capital flows in the form of FDI are not explicitly modeled.

${ }^{5}$ On the other hand, a model that can generate low interest rate through precautionary savings would also imply low MPK (i.e., Aiyagari, 1994), but in the data countries with saving gluts have high MPKs.
} 
aggregate capital is fixed in each country and there is no labor market, and so there are no crosscountry fixed capital flows by assumption. ${ }^{6}$ Most importantly, FDI is modeled by MQR as purchases of foreign firms' equities. While foreign equity holding is a special form of FDI, it is no longer the major form of FDI. Data show that the currently dominant form of FDI involves setting up new firms or establishing new affiliations in foreign countries by exporting technology-embodied fixed capital and receiving factor payments as capital owners. For example, based on the total nonfinancial capital outflows from the U.S. to the rest of the world (ROW), the particular form of FDI assumed in the model of MQR (2009) accounts for less than $38 \%$ of total FDI, leaving more than $62 \%$ of U.S. FDI unexplained. In contrast, the specific form of FDI studied in our paper accounts for more than $76 \%$ of U.S. FDI outflows to China. Also, the new establishment of affiliations (or firms) with ownership fully belonging to foreigners accounts for $80 \%$ of China's total inward FDI from developed countries in 2009 and 2010 and this number is still growing. ${ }^{7}$ Therefore, our approach represents a big step toward understanding the mechanisms of FDI and its role in global imbalances.

Moreover, the model of MQR generates a trade surplus for the U.S. in the longer term. In their model the interest payment on the inflow of financial capital from developing countries outweigh the returns from outward FDI, and so the U.S. net foreign income payment is positive in the steady state. Hence, their model does not support the notion that the persistent U.S. trade deficits with China and the ROW may in fact be sustainable in the long run. ${ }^{8}$

The rest of the paper is organized as follows. Section 2 presents stylized facts about the two-way capital flows between China (representing the South) and the U.S. (representing the North). Section 3 introduces an extremely simple toy model to illustrate how our story can explain the stylized facts. Section 4 presents our full-fledged model. Section 5 studies the conditions for generating two-way capital flows. Section 6 provides quantitative predictions and section 7 concludes the paper.

\section{Stylized Facts}

We decompose global capital flows into financial capital flows and nonfinancial capital (FDI) flows. We first use data from China to represent developing countries (South) and those from the U.S. to

\footnotetext{
${ }^{6}$ However, they allow nonreproducible managerial capital or human capital to be reallocated across borders.

${ }^{7}$ See the Data Appendix (C.1, available upon request) for details of the classifications and compositions of FDI in the U.S. and China.

${ }^{8}$ In addition, the model of MQR rules out any aggregate risks to reduce computational burdens. Without aggregate uncertainty, their model generates only a small risk premium for the rate of return to FDI (i.e., holdings of foreign capital stocks), and this small risk premium leads to a positive net factor payment (interest payment minus FDI earnings). To overcome the computational challenge under aggregate risk, Chien and Naknoi (2011) simplify the MQR model to a pure endowment economy and use a special algorithm to numerically solve the model. They show that with aggregate uncertainty (stochastic output growth), the model can generate a large risk premium between equity and risk-free bonds and thus is able to generate long-term trade deficits for the U.S. However, their model is not suited for studying the two-way capital flows discussed in this paper because it is an endowment economy without capital. Our approach can easily handle any number of aggregate shocks without having to rely on aggregate risk to generate high returns to FDI because we consider an entirely different channel of FDI.
} 
represent the developed world (North). ${ }^{9,10}$ We begin with the following three observations.

1 China (the U.S.) is a net exporter (importer) of financial capital and a net importer (exporter) of FDI.

Figure 1A shows the net foreign asset positions of the U.S. with respect to China. In particular, the blue line with a positive trend shows the accumulated net FDI outflows from the U.S. to China as a share of U.S. GDP (left axis), and the red line with a negative trend shows the accumulated net financial capital inflows from China to the U.S. as a share of U.S. GDP (right axis). Figure 1B plots the net foreign asset positions of China against ROW (mostly developed countries). The red line with an upward trend indicates China's total accumulated net financial capital outflows, which accounts for about 50\% of the country's GDP in 2010. The blue line with a downward trend shows China's total accumulated net FDI inflows, which account for about $20 \%$ of the country's GDP in $2010 . .^{11}$

A. US Capital Flows vs. China

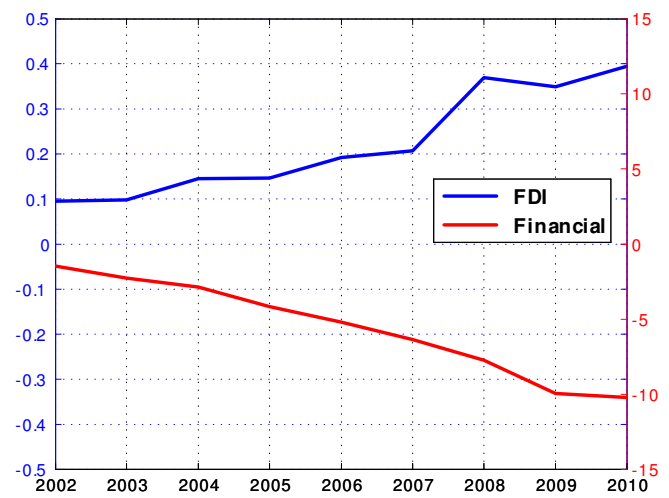

B. China Capital Flows vs. ROW

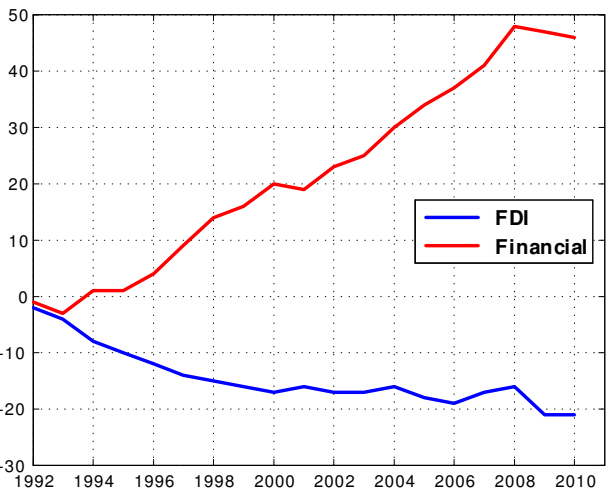

Figure 1. Two-Way Capital Flows

2 China has a significantly higher rate of return to fixed capital and a significantly lower rate of return to financial capital than the U.S.

\footnotetext{
${ }^{9}$ Appendix C.1 (available upon request) provides details about these data series.

${ }^{10}$ Following the existing literature (e.g., Ju and Wei, 2010), we define net FDI outflows $=[F D I$ Asset $-F D I$ Liability], and net financial capital outflows $=[$ total foreign asset - FDI asset $]-[$ total foreign liability - FDI liability]. This definition is equivalent to define net financial capital outflow $=$ [Portfolio equity assets - Portfolio equity liabilities] + [Debt assets - Debt liabilities $]+[$ financial derivatives assets - financial derivatives liabilities] + [Foreign Exchange Reserves - gold]. The series are measured in billions of dollars.

${ }^{11}$ Because China has been growing much faster than the ROW, its FDI inflows appear to have slowed in recent years relative to its GDP (Figure 1B). However, absolute magnitude has been accelerating. For example, the U.S. FDI to China does not show such a declining pattern as a share of U.S. GDP (Figure 1A).
} 
A. Rate of Return to Capital

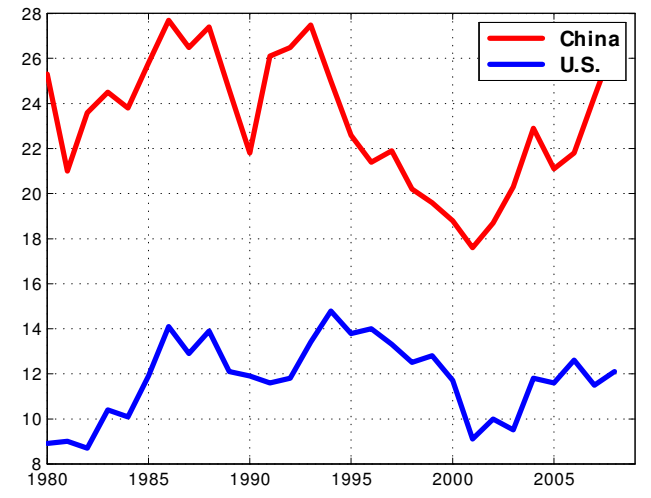

B. Real Interest Rate

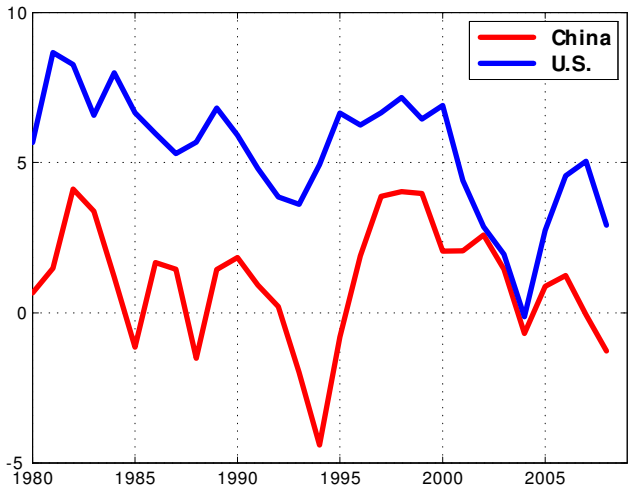

Figure 2. Differential Asset Returns in China and U.S.

Figure 2A compares the before-tax real rates of return to fixed capital in China (red) and the U.S (blue). China's capital return stayed at a very high level over the entire sample period, with a mean of $23 \%$ per year. In contrast, the rate of return to fixed capital in the U.S. was significantly below that of China, with a mean of about $10 \%$ per year. The spread remained highly persistent over the entire sample period with only a slight decline in the mid-1990s. ${ }^{12}$

Table 1. Real Interest Rates (Annual, 1990-2011)

\begin{tabular}{|c|c|c|c|c|c|c|c|}
\hline$\overline{\text { Period }}$ & 1 Mont & 3 Month & 6 Month & 1 1 Year & 2 Year & "3 Year & 5 Year \\
\hline \multicolumn{8}{|c|}{ China (Inflation Rate $=4.78 \%$ ) } \\
\hline Deposit rate $(\%)$ & -3.60 & -1.79 & -0.93 & -0.13 & 0.44 & 1.01 & 1.62 \\
\hline Govt. bond (\%) & & -2.67 & -2.58 & -1.88 & & -1.77 & -1.35 \\
\hline \multicolumn{8}{|c|}{ U.S. (Inflation Rate $=2.75 \%$ ) } \\
\hline $\mathrm{CD}(\%)$ & 1.07 & 1.15 & 1.26 & & & & \\
\hline T-bill (\%) & & 0.69 & 0.80 & 1.18 & & & 2.06 \\
\hline
\end{tabular}

Figure $2 \mathrm{~B}$ shows that there is also a systematic difference in the rates of return to financial capital between the two countries, but the spread is reversed. For example, the annual real interest rate (defined as the risk-adjusted annual lending rate) in the U.S. (blue) is about 6\% (per unit of risk) on average, whereas that in China (red) is about 1\% (per unit of risk) on average. Table 1 also shows a systematic cross-country gap of about 3 percentage points in the real interest rates (not adjusted for risk) when bank deposit rates and government bond rates are compared. ${ }^{13}$

\footnotetext{
${ }^{12}$ The after-tax rate of return in China was about $18 \%$ whereas that in the U.S. was about $7 \%$. Therefore, even after taking tax adjustments into account, the rates of return to fixed capital in the two countries were still significantly different. We also calculated the U.S. rate of return to fixed capital through Poterba's (1998) method but the result changes little.

${ }^{13}$ Risk adjustment means dividing the interest rate by its standard deviations. The real rates in Table 1 are computed using the CPI inflation rate in each country. U.S. data are from FRED (Federal Reserve Bank of St. Louis). Chinese data are from the People's Bank of China.
} 
3 China has a less developed financial market than the U.S.

Figure 3 shows that private credit-to-GDP ratios in both China and the U.S. have been rising gradually over time, which may indicate financial improvement in both countries. However, the disparity between the two countries is large and shows no signs of diminishing over time. We obtain similar results when using other measures of financial development, such as the financial development index in the World Competitiveness Report. ${ }^{14}$

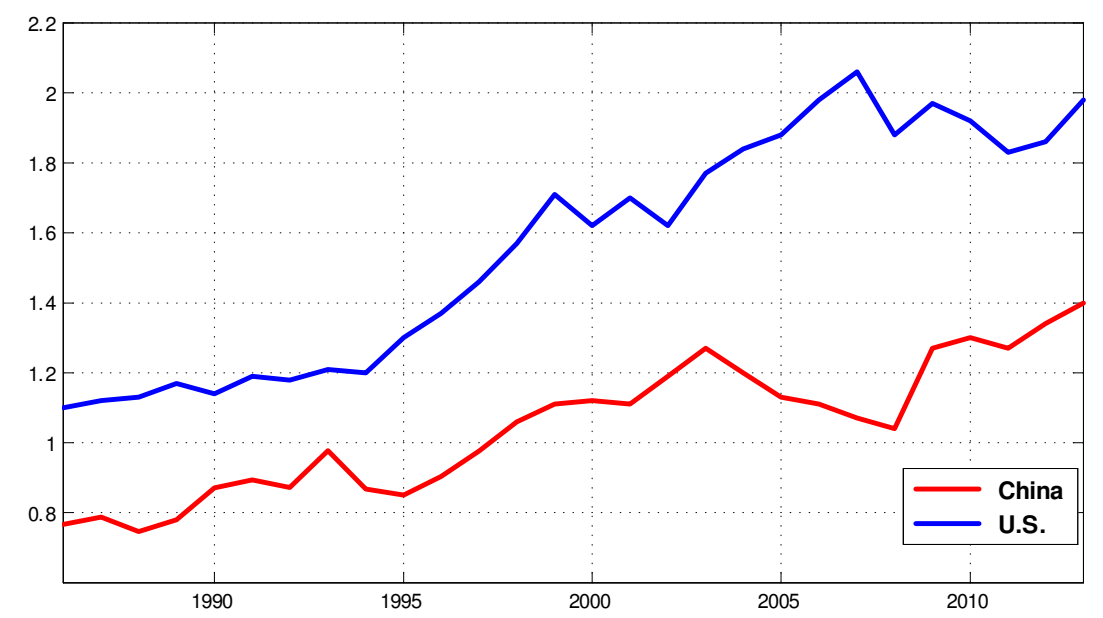

Figure 3. Financial Development in China and U.S.

The two-way capital flow pattern shown in Figure 1 also exists in other major emerging economies and developed countries. We first look at the two-way capital flow pattern for the developed world, using data from 21 developed countries for the period 2000-2011. ${ }^{15}$ Figure 4A shows that the developed countries as a whole, just like the U.S., exhibits a very significant twoway flow pattern, with net financial capital inflows (red line) and net FDI outflows (blue line). Also, the net total asset position for the developed world is negative (dashed line), suggesting the reverse capital-flow pattern. We next look at the two-way capital flow pattern for the emerging markets, using data from 22 emerging economies analyzed by Ju and Wei (2010). ${ }^{16}$ The data set was updated from Lane and Milesi-Ferretti (2007) and the sample period is also from 2000 to 2011.

\footnotetext{
${ }^{14}$ We follow the existing literature (e.g., King and Levine, 1993) by using the total private credit-to-GDP ratio as a measure of financial development because this variable captures the ability of financial intermediaries to allocate credit. A persistently higher ratio thus indicates a better financial system. The World Competitiveness Report (WCR) is released by the World Development Forum each year and contains several indices for financial development. Suppose we use Financial Market Sophistication index as an indicator for the financial development, the index is also significantly lower for China than for the U.S. Moreover, the gap between the two countries also remains highly stable over time. Appendix C.2 presents more detailed empirical evidences on the measured gap of financial development between China and the U.S.

${ }^{15}$ These countries are Australia, Austria, Belgium, Canada, Denmark, Finland, France, Germany, Greece, Ireland, Italy, Japan, Netherlands, New Zealand, Norway, Portugal, Spain, Sweden, Switzerland, U.K., and the U.S.

${ }^{16}$ This country group includes Argentina, Brazil, Chile, China, Colombia, Egypt, Hong Kong SAR, India, Indonesia, Israel, Korea, Malaysia, Mexico, Morocco, Pakistan, Peru, Philippines, Singapore, South Africa, Thailand, Turkey, and Venezuela.
} 
Figure 4B shows an upward trend in net financial capital outflows (red line) and a negative trend in net FDI inflows (blue line), just the opposite of the trends in developed world.

A. Developed Markets

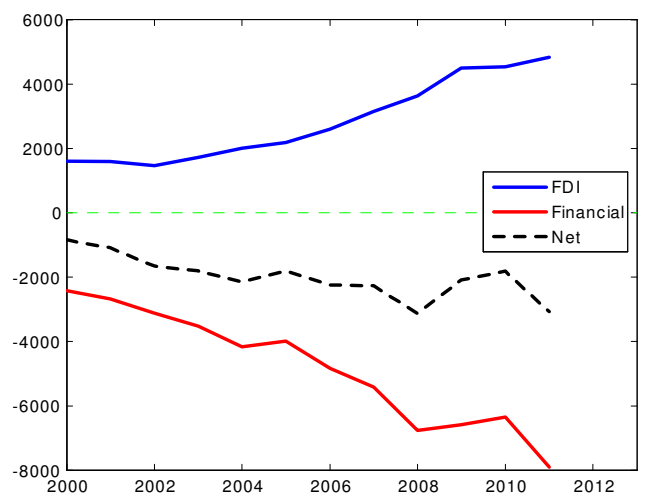

B. Emerging Markets

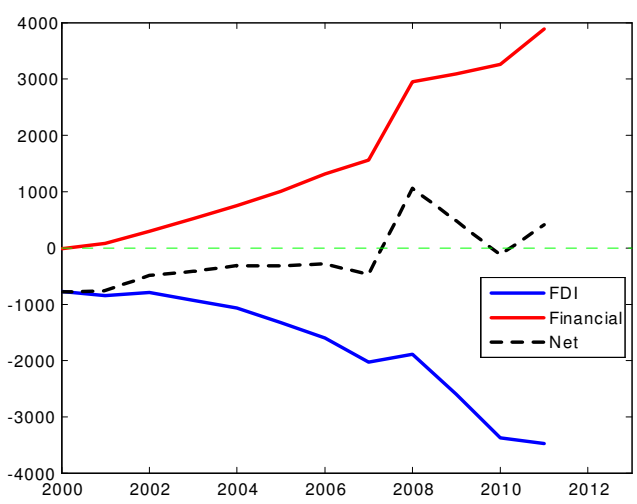

Figure 4. International Two-Way Capital Flows.

\section{A Toy Model}

We present first an extremely simple, two-country general-equilibrium toy model to illustrate the intuition and main thrust of our story, before proceeding to a more sophisticated full-fledged dynamic general equilibrium model in the next section (for calibration and quantitative exercises). The toy model economy has two countries, labeled $h$ (home) and $f$ (foreign). Each country is populated by a continuum of heterogeneous households indexed by $i \in[0,1]$, and a representative firm. The foreign country is frictionless and the home country has financial frictions. We focus on the home country and drop the country index unless confusion may arise.

Households. Households live for two periods, period 1 and 2. They each supply inelastically one unit of labor in period 2 and consume in both periods, the first period income is drawn from an endowment and the second period income from past savings in period 1 and wage income in period 2. In particular, a household $i$ maximizes the lifetime (linear) utility,

$$
\theta_{i} c_{1 i}+\beta c_{2 i}
$$

subject to the following budget constraints and borrowing constraint:

$$
\begin{aligned}
c_{1 i} & =H-s_{i} \\
c_{2 i} & =s_{i} R_{b}+W+D \\
s_{i} & \geq-\bar{B},
\end{aligned}
$$

where $c_{1 i} \geq 0$ is consumption in period $1, c_{2 i} \geq 0$ is consumption in period $2, H$ is endowment in period $1, R_{b}$ is the gross interest rate on savings, $W$ is wage income in period $2, D$ is profit income 
from firms in period 2 , and $\bar{B} \geq 0$ is the maximum amount a household can borrow in period 1. Also, $\theta_{i}$ is a random preference shock drawn independently and identically from a common distribution function. For simplicity, assume that $\theta_{i}$ takes the value of 1 with probability $\pi$ and the value of $\tau<1$ with probability $1-\pi$.

Firms. A representative firm produces output to meet households' consumption demand in period 1. Its problem is to choose capital $(K)$ and labor $(N)$ to solve

$$
\Pi \equiv \max _{\{K, N\}}\left\{A K^{\alpha} N^{1-\alpha}-W N-R_{b} K\right\}
$$

subject to the borrowing constraint

$$
K \leq \bar{K}
$$

The firm's problem can be simplified by substituting out its optimal labor choice $N$ in the profit function. Given $K$ and the real wage $W$, the first-order condition of labor choice implies the following optimal labor demand:

$$
N=\left[\frac{A(1-\alpha)}{W}\right]^{\frac{1}{\alpha}} K
$$

Hence, we have $A K^{\alpha} N^{1-\alpha}-W N=\alpha A\left[\frac{A(1-\alpha)}{W}\right]^{\frac{1-\alpha}{\alpha}} K \equiv R_{k} K$. The firm's problem then becomes $\Pi=\max _{K}\left(R_{k}-R_{b}\right) K$ subject to the constraint (6). Thus, the firm's profit is simply the difference between the rate of return to capital $\left(R_{k} K\right)$ and its borrowing costs $\left(R_{b} K\right)$. We normalize the equilibrium optimal capital stock to one in the absence of financial frictions (borrowing constraints) by assuming $\alpha A=\beta^{-1}$. We make two additional assumptions: $(1-\pi) H>1+\pi \bar{B}$ and $\bar{K}<1$, to ensure that the borrowing constraint of the households (4) will bind if $\theta_{i}=1$ and that for the firm (6) will bind in equilibrium.

Equilibrium in the Closed Economy. With the labor market clearing condition $N=1$, equation (7) implies $W=(1-\alpha) A K^{\alpha}$. It then follows that $R_{k}=\alpha A K^{\alpha-1}$. In other words, the real wage is the marginal product of labor and the rate of return to capital equals the marginal product of capital. ${ }^{17}$ Hence, in equilibrium we have $R_{b}=\frac{\tau}{\beta}<\frac{1}{\beta}$ and $R_{k}=\frac{1}{\beta} \bar{K}^{\alpha-1}>\frac{1}{\beta}$,

$$
s_{i}=\left\{\begin{array}{cc}
-\bar{B} & \text { if } \theta_{i}=1 \\
\frac{1}{1-\pi}[\bar{K}+\pi \bar{B}] & \text { if } \theta_{i}=\tau
\end{array}\right.
$$

and consumptions $c_{1 i}$ and $c_{2 i}$ are given by (2) and (3), respectively, and the equilibrium capital stock of the firm is $K=\bar{K} \cdot{ }^{18}$

\footnotetext{
${ }^{17}$ The market clearing conditions are: $\int_{0}^{1} s_{i} d i=K, \int_{0}^{1} c_{1 i} d i+K=H, \int_{0}^{1} N_{i}=N=1$, and $\int_{0}^{1} c_{2 i} d j=A K^{\alpha} N^{1-\alpha}$.

${ }^{18}$ The proof is straightforward. First given $R_{K}>R_{b}$, the firm wants to borrow as much as possible to invest,
} 
To gain a better understanding of the distortions in asset returns caused by borrowing constraints, we now characterize the equilibrium without financial frictions: The equilibrium without borrowing constraints (4) and (6) satisfies $R_{b}=R_{k}=\frac{1}{\beta}, K_{j}=K=1$, and $s_{i}=H$ if $\theta_{i}=\tau$ and $s_{i}=\frac{1}{\pi}[1-(1-\pi) H]$ if $\theta_{i}=1$. It is easy to verify these equilibrium conditions. First, notice that without borrowing constraint (6), competition for loanable funds will then drive $R_{k}$ to equalize $R_{b}$. Second, $R_{b}$ must be equal to $1 / \beta$ in equilibrium, because no households would be willing to lend (borrow) if $R_{b}<1 / \beta\left(R_{b}>1 / \beta\right)$.

Comparing the two equilibria with and without financial frictions, we learn that borrowing constraints reduce the rate of return to financial assets (savings) but increase the rate of return to physical capital for the home country. Thus, if the home country is financially integrated with a foreign country with no or less financial frictions, financial capital will flow from home (South) to abroad (North) because of a higher interest rate abroad, whereas fixed capital will flow in the opposite direction because of a higher capital return at home. We now proceed to characterize the open-economy equilibrium when the two countries are financially integrated.

Equilibrium in the Open Economy. ${ }^{19}$ In the open-economy equilibrium, under arbitrage we must have $R_{b}^{f}=\frac{1}{\beta}=R_{k}^{f}, R_{b}=\frac{1}{\beta}$ and $R_{k}=\frac{1}{\beta}+\varphi$ for any $\varphi<\frac{1}{\beta} \min \left(1-\tau, \bar{K}^{\alpha-1}-1\right)$. The intuition is as follows. First, since there are no borrowing constraints in the foreign country, we must have $R_{b}^{f}=\frac{1}{\beta}=R_{k}^{f}$. Second, for the households in the home country, the domestic bond return is $R_{b}$ while the foreign bond return is $1 / \beta$. Since the two bonds are perfect substitutes, arbitrage implies $R_{b}=1 / \beta$. Finally, from the foreign firms' point of view, one unit of domestic investment yields $R_{k}^{f}=\frac{1}{\beta}$, and one unit of investment abroad yields $R_{k}-\varphi$. This implies in that so the constraint (6) binds: $K=\bar{K}$. Since $R_{b}=\frac{\tau}{\beta}<\frac{1}{\beta}$, the impatient households with $\theta_{i}=1$ opt to borrow as much as possible, so $s_{i}=-\bar{B}$. For the patient households with $\theta_{i}=\tau$ their saving is determined by the aggregate capital (bond) market clearing condition $\int_{\theta_{i}=\tau} s_{i} d i=\bar{K}+\pi \bar{B}$, where the left-hand side is total savings of the patient households with $\theta_{i}=\tau$, and the right-hand side is total borrowing by the firm and by the impatient households (with $\left.\theta_{i}=1\right)$. This is the case because households can only borrow from each other in a closed economy. By imposing a symmetry equilibrium, we obtain the second line in equation (8). Notice by assumption $\frac{1}{1-\pi}[\bar{K}+\pi \bar{S}]<H$, so consumption of the impatient in the first period is strictly positive.

${ }^{19}$ In the open economy, households in each country can save in both domestic bonds and foreign bonds, and firms can invest both at home and abroad by shipping physical capital across boarders. When the firm sends capital abroad to produce output, it hires foreign workers and pays foreign wages. We assume there is a transaction cost $\varphi$ in shipping physical capital abroad. So the home country household budget constraints change to $c_{i 1}=H-s_{i}-\tilde{s}_{i}$ and $c_{i 2}=s_{i} R_{b}+W+D+\tilde{s}_{i} R_{b}^{f}$, where $\tilde{s}_{i} \geq 0$ is the foreign bond holdings, $R_{b}^{f}$ denotes the foreign interest rate. The borrowing constraint changes to $s_{i}+\tilde{s}_{i} \geq-\bar{B}$. The home country firm can invest $u_{j} \in[0,1]$ fraction of its capital in the foreign country. The firm's problem becomes

$$
\max _{\{u, N, X, K\}}\left\{((1-u) K)^{\alpha} N^{1-\alpha}-W^{h} N+(u K)^{\alpha} X^{1-\alpha}-W^{f} X-\varphi u K-R_{b} K\right\},
$$

where $W^{f}$ denotes foreign wage and $X_{j}$ foreign labor. The borrowing constraint of the firm is still given by equation (6). The households and firm in the foreign country solve similar problems except they do not face borrowing constraints. 
equilibrium we must have $R_{k}-\varphi=R_{k}^{f}=\frac{1}{\beta}$, or $R_{k}=\frac{1}{\beta}+\varphi$. Notice that the local households will hold foreign bonds because $R_{b}^{f}>R_{b}$ in autarky. Similarly, since $R_{k}=\frac{1}{\beta}+\varphi>R_{k}^{f}$, the local firm will not invest in the foreign country. Because $R_{k}>R_{b}$, the borrowing constraint (6) will be binding, $K_{j}=\bar{K}$, in the home country. ${ }^{20}$ The amount of physical capital that is imported from the foreign country is $(1+\beta \varphi)^{\frac{1}{\alpha-1}}-\bar{K}>0$, and the amount of financial capital going to the foreign country is given by $(1-\pi) H-\bar{K}-\pi \bar{B}>0$. Notice that the transaction cost $\varphi$ determines the size of physical capital flows.

Firm Heterogeneity. The toy model illustrates that financial frictions alone can in principle explain the two-way capital flows between developing countries and developed countries. However the simple toy model has a counterfactual implication about the aggregate domestic saving rates in the two countries. The saving rate in the home country is $\frac{\bar{K}}{H}$, while the saving rate in the foreign country is $\frac{1}{H}$. Since by assumption $\bar{K}<1$, we have $\frac{\bar{K}}{H}<\frac{1}{H}$. However, in the data developing countries tend to have a higher aggregate saving rate than developed countries - the so-called "savings glut". To solve this problem, we will introduce firm heterogeneity into the full-fledged model.

\section{The Full-Fledged DSGE Model}

The full-fledged two-country model is an infinite horizon model with standard preferences and production technologies. The model yields the same qualitative predictions for two-way capital flows as the toy model, but is more sophisticated to permit calibrations and quantitative studies. As in the toy model, the two countries are indicated by $h$ and $f$. There are two types heterogeneous agents in both countries. We use $i \in[0,1]$ to index heterogeneous households and $j \in[0,1]$ to index heterogeneous firms. Each country issues its own country-specific bonds, and neither country can issue foreign bonds. To simplify the analysis we assume that bonds are the only tradable financial assets between the two countries. ${ }^{21}$ However, firms can invest in the foreign country through FDI. We use the tightness of borrowing constraints to indicate the degree of financial development in each country, as is standard in the literature (e.g., MQR, 2009). Because firms are heterogeneous, each consumer holds a portfolio of firms' equities, taking as given the market prices of the portfolio.

We focus our analysis on the home country in what follows. The foreign country's problem is analogous. Whenever convenient, we use $\ell=\{h, f\}$ as the country index and use $\ell_{c}$ to denote the

\footnotetext{
${ }^{20}$ Also note, since $\frac{\tau}{\beta}<R_{b}$, we must have $s_{i}+\tilde{s}_{i}=\left\{\begin{array}{cc}-\bar{B} & \text { if } \theta_{i}=1, \\ H & \text { if } \theta_{i}=\tau .\end{array}\right.$

${ }^{21}$ Allowing households to hold foreign firms' equities does not change our results qualitatively. This simplifying assumption is made so we can focus on FDI in the form of shipping fixed capital across borders and not mingle it with acquiring the ownership of foreign firms through equity holdings.
} 
counterpart of country $\ell$.

\subsection{Households}

In each period $t$, household $i$ derives utility from consumption $c_{i t}$ and leisure $1-n_{i t}$. The instantaneous utility function is quasi-linear, $\theta_{i t} \log c_{i t}-\psi n_{i t}$, where the preference shock $\theta_{i t}$ is drawn from a common distribution $F(\theta)=\operatorname{Pr}\left[\theta_{i} \leq \theta\right]$ with support $\left[\theta_{\min }, \theta_{\max }\right]$. Each period is divided into two subperiods. The idiosyncratic preference shocks are realized in the second subperiod. Each household $i$ chooses labor supply $n_{i t}$ in the first subperiod without observing $\theta_{i t}$. This implies that households cannot use the labor supply to insure themselves against the idiosyncratic shocks. Consumption and saving decisions are made in the second subperiod after preference shocks are realized. Specifically, after choosing $n_{i t}$ and upon observing $\theta_{i t}$, household $i$ chooses consumption $c_{i t}$, savings in domestic bonds $s_{i t+1}$, savings in foreign bonds $\tilde{s}_{i t+1}$, and savings in firms' equities $a_{i t+1}$. As shown by Wen $(2009,2011)$, such an information structure permits closed-form solutions for household decision rules with incomplete markets and borrowing constraints.

Denoting $Q_{t}$ as the price index of a portfolio of firms' equities (stocks) and $D_{t}$ as the aggregate dividend paid to the portfolio (capturing the rate of return to stocks), the borrowing constraint facing each household is specified as

$$
s_{i t+1}+\tilde{s}_{i t+1}+a_{i t+1} Q_{t} \geq-B_{t}
$$

where $a_{i t+1}$ is the share of the portfolio newly purchased by the household in period $t$, and $B_{t} \geq 0$ is an exogenously specified borrowing limit (as in Aiyagari, 1994), To facilitate analysis, we assume that $B_{t}$ is proportional to the value of equity, $B_{t}=b Q_{t}$, where $b$ captures the degree of financial development on the household side.

Since countries cannot issue foreign bonds (although households can hold foreign bonds), we have

$$
\tilde{s}_{i t+1} \geq 0
$$

for all $i \in[0,1]$. This implies that if a country opts to borrow abroad, it must sell its home bonds to foreigners. ${ }^{22}$

Taking as given the real wage $W_{t}$ and the real interest rates at home and abroad, household $i$ solves

$$
\max _{\left\{n_{i t}, c_{i t}, s_{i t+1}, \tilde{s}_{i t+1}, a_{i t+1}\right\}} E_{0}\left[\sum_{t=0}^{\infty} \beta^{t}\left(\theta_{i t} \log c_{i t}-\psi n_{i t}\right)\right],
$$

\footnotetext{
${ }^{22}$ The constraint in equation (10) is not essential. Our general results hold if we simply allow an international bond with a world interest rate. However, to capture the different interest rates in China and the U.S. both before and after financial liberalization, we need to have domestic and foreign bonds with asymmetric trading costs.
} 
subject to constraints (9) and (10), as well as the budget constraint

$$
c_{i t}+s_{i t+1}+\tilde{s}_{i t+1}+a_{i t+1} Q_{t} \leq R_{b t-1}^{h} s_{i t}+R_{b t-1}^{f} \tilde{s}_{i t}-\gamma_{s} \frac{\tilde{s}_{i t}^{1+\tau}}{1+\tau}+W_{t} n_{i t}+\left(Q_{t}+D_{t}\right) a_{i t}
$$

where $\left\{R_{b t}^{h}, R_{b t}^{f}\right\}$ denote domestic and foreign interest rates, respectively, and $\gamma_{s} \frac{\tilde{s}_{i t}^{1+\tau}}{1+\tau}$ denotes the convex cross-border trading costs for purchasing foreign bonds (with $\gamma_{s} \geq 0$ and $\tau>0$ ). ${ }^{23}$

\subsection{Firms}

Each firm $j$ with capital stock $K_{j t}$ can choose to produce both at home and abroad. A firm combines labor and capital to produce output through the Cobb-Douglas technology $Y_{j t}=K_{j t}^{\alpha} N_{j t}^{1-\alpha}$. Each firm accumulates productive capital according to the law of motion,

$$
K_{j t+1}=(1-\delta) K_{j t}+\varepsilon_{j t} I_{j t}
$$

where $I_{j t}$ denotes investment expenditures and $\varepsilon_{j t} \in R^{+}$is an idiosyncratic shock to the marginal efficiency of investment, which is i.i.d across firms and over time (as in Wang and Wen, 2012). We denote the cumulative density function of $\varepsilon$ by $\Phi(\varepsilon)$.

With heterogeneous households, the firm's dynamic programming problem becomes slightly more complicated. The first step is to find the correct discount factor. We follow Hansen and Richard (1987), Cochrane (1991), and Wang, Xu and Xu (2011) to assume that there exists a sequence of prices $\left\{P_{t}\right\}_{t=0}^{\infty}$ such that a firm's expected value is determined by

$$
V_{j t}=E_{t}\left[\sum_{\tau=0}^{\infty} \frac{P_{t+\tau}}{P_{t}} D_{j t+\tau}\right]
$$

where $\left\{D_{j t+\tau}\right\}_{\tau=0}^{\infty}$ is the dividend flows generated by firm $j$ and the expectation operator $E$ is taken on the idiosyncratic shock $\varepsilon_{j t}$. Denoting $\Lambda_{t} \equiv P_{t} / \rho^{t}$, where $\rho<1$, we can rewrite the firm's expected value as $V_{j t}=E_{t}\left[\sum_{\tau=0}^{\infty} \rho^{\tau} \frac{\Lambda_{t+\tau}}{\Lambda_{t}} D_{j t+\tau}\right]$, which can be rewritten recursively as ${ }^{24}$

$$
V_{j t}=\int\left(D_{j t}+\rho E_{t} \frac{\Lambda_{t+1}}{\Lambda_{t}} V_{j t+1}\right) d \Phi
$$

\footnotetext{
${ }^{23}$ We assume that there exist cross-border trading costs in purchasing foreign bonds and the costs are increasing in the trading volume. This assumption is not necessary for our general results but is needed only to capture the transitional dynamics of international financial capital flows after financial liberalization. China opens its capital markets only gradually; even today its capital markets are not completely open. So the rationale for such trading costs includes capital controls in developing countries in addition to other transaction costs discussed in the literature. However, our qualitative results do not hinge on the assumption of trading costs and our model nests the standard models with zero trading costs as a special case.

${ }^{24}$ Notice that by our definition of firm's value, the value function $V_{j t}$ is independent of the firm's idiosyncratic shock $\varepsilon_{j t}$ in period $t$. This approach simplifies our notation but is not essential for our results. Alternatively, we could define a firm's value as $V_{j t}=D_{j t}+\rho E_{t} \frac{\Lambda_{t+1}}{\Lambda_{t}} V_{j t+1}$, so that it depends on period-t's shock $\varepsilon_{j t}$.
} 
Notice that because of heterogeneity on the household side, $\rho$ does not necessarily equal the household's discount factor $\beta$. With the firm value given by equation (15), the firm's problem is then to maximize its expected value $V_{j t}$ by choosing labor demand, capital allocation (the share of FDI), and the level of fixed investment.

In the beginning of each period, firm $j$ decides to allocate $1-u_{j t}$ fraction of its fixed capital stock $\left(K_{j t}\right)$ at home and the remaining $u_{j t}$ fraction of the capital stock abroad. ${ }^{25}$ We assume that there are costs involved in reallocating fixed capital across borders and a firm needs to pay the amount $\gamma_{k} \frac{u_{j t}^{1+\chi}}{1+\chi} K_{j t}$ to move $u_{j t}$ fraction of its capital stock abroad. This cost is analogous to the transaction cost $\varphi$ in the toy model. ${ }^{26}$ The parameters $\gamma_{k}(>0)$ and $\chi(>0)$ control capital mobility and the extent of openness for the fixed capital market. For example, when $\gamma_{k}=\infty$, cross-border fixed capital flows are completely shut down. When $\gamma_{k}=0$, FDI flows can be adjusted instantaneously without any costs. This parameter also captures institutional costs for setting up foreign business and policies designed to attract FDI through reducing such frictions.

The optimal choices of $u_{j t}$ as well as labor inputs are static. Given the capital stock $K_{j t}$, firm $j$ 's operating profits $\Pi_{j t}$ can be derived through the following maximization problem:

$$
\Pi_{j t} \equiv \max _{\left\{u_{j t}, N_{j t}, X_{j t}\right\}}\left\{\left(\left(1-u_{j t}\right) K_{j t}\right)^{\alpha} N_{j t}^{1-\alpha}-W_{t}^{h} N_{j t}+\left(u_{j t} K_{j t}\right)^{\alpha} X_{j t}^{1-\alpha}-W_{t}^{f} X_{j t}-\gamma_{k} \frac{u_{j t}^{1+\chi}}{1+\chi} K_{j t}\right\}
$$

where $W_{t}^{h}$ and $W_{t}^{f}$ are the real wage in the home country and the foreign country, respectively, $N_{j t}$ the demand for domestic labor, and $X_{j t}$ the demand for foreign labor. Let $r_{t}$ denote the marginal product of domestic capital $\left(\frac{\partial Y_{j t}}{\partial\left[\left(1-u_{j t}\right) K_{j t}\right]}\right)$ and $R_{k t}$ the gross MPK (including capital operating both at home and abroad). Appendix A.1 shows that $r_{t}$ and $R_{k t}$ are both independent of firm-specific shocks and are related by the following relationship:

$$
R_{k t}=r_{t}+\mathbf{1}_{r_{t}^{f}>r_{t}}\left[\frac{\chi}{1+\chi} \gamma_{k}^{-\frac{1}{\chi}}\left(r_{t}^{f}-r_{t}\right)^{\frac{1+\chi}{\chi}}\right]
$$

where $\mathbf{1}_{r_{t}^{f}>r_{t}}$ is an index function that takes value of 1 whenever $r_{t}^{f}>r_{t}$ and 0 otherwise. We now define the MPK as the gross marginal product of capital net of depreciation rate:

$$
M P K_{t} \equiv R_{k t}-\delta .
$$

\footnotetext{
${ }^{25}$ The outward FDI of the home country in our model is thus $u_{t} K_{t}$. According to the BEA data source, this form of FDI dominates other forms of FDI flows.

${ }^{26}$ Even though financial and fixed capital move in opposite directions, net aggregate capital (financial plus fixed) still shows the reversed pattern noticed by Lucas (1990). The net foreign asset position of a country (the sum of net flows in financial and fixed capitals) is determined by the liquidity (mobility) of the two forms of capital. Thus the transaction costs allow our model to quantitatively match the imbalanced two-way capital flows between China and the U.S.
} 
Notice that in financial autarky (no cross-border capital flows), $M P K_{t}=r_{t}-\delta$, which is the conventional definition of the MPK used in the empirical literature (e.g., Bai et al., 2006).

We now discuss the firm's dynamic optimization problem in choosing investment $I_{j t}$. In particular, we assume that the investment is chosen after the idiosyncratic efficiency shock $\varepsilon_{j t}$ is observed. Let $V_{t}\left(K_{j t}\right)$ denote the expected value of the firm with capital stock $K_{j t}$ at the beginning of period $t$ before observing $\varepsilon_{j t}$. This value function can now be defined recursively using the proper discount factor $\rho \frac{\Lambda_{t+1}}{\Lambda_{t}}$ as

$$
V_{t}\left(K_{j t}\right)=\int \max _{I_{j t}}\left[\Pi_{j t}-I_{j t}+\rho E_{t} \frac{\Lambda_{t+1}}{\Lambda_{t}} V_{t+1}\left((1-\delta) K_{j t}+\varepsilon_{j t} I_{j t}\right)\right] d \Phi
$$

where $\Pi_{j t}-I_{j t} \equiv D_{j t}$ is dividend. We assume that a firm can use both internal funds, $\Pi_{j t}\left(K_{j t}\right)$, and outside funds (from borrowing), $L_{j t}$, to finance investment. Hence, the maximum investment is subject to the constraint

$$
I_{j t} \leq L_{j t}+\Pi_{j t}
$$

For simplicity, we assume that the external funds are raised through intraperiod loans: Firms can borrow from each other through a financial intermediary at the beginning of period $t$ and pay back the loan at the end of period $t$ with zero interest rate. ${ }^{27}$ Since in each period some firms will opt not to invest $\left(I_{j t}=0\right)$, financial intermediaries can lend these inactive firms' savings to investing firms after paying dividends to equity holders (households).

Loans are subject to collateral constraints, as in Kiyotaki and Moore (1997). That is, firm $j$ is allowed to pledge a fraction $\xi \in(0,1]$ of its fixed capital stock $K_{j t}$ at the beginning of period $t$ as collateral. In general, the parameter $\xi$ represents the extent of financial market imperfections - the higher the value of $\xi$, the more a firm can borrow and thus the more advanced the financial market. At the end of period $t$, the market value of the pledged collateral is equal to $\rho \frac{\Lambda_{t+1}}{\Lambda_{t}} V_{t+1}\left(\xi K_{j t}\right)$, which is the present value of the collateral of firm $j$ at the beginning of period $t+1$, or equivalently the value of a firm that owns collateralizable capital stock $\xi K_{j t}$. The amount of loans $L_{j t}$ cannot exceed this collateral value because of limited contract enforcement. Thus, we impose the following collateral constraint:

$$
L_{j t} \leq \rho \frac{\Lambda_{t+1}}{\Lambda_{t}} V_{t+1}\left(\xi K_{j t}\right)
$$

\footnotetext{
${ }^{27}$ Because of irreversible investment and the option value of waiting, unproductive firms with low $\varepsilon$ shock opt not to invest and prefer saving through the financial intermediary (as a form of liquidity). The zero interest rate is an innocuous assumption. Allowing for a one-period loan with positive interest rate does not change our results. This is equivalent to a one-period private bond market where firms lend and borrow from each other by issuing (purchasing) private bonds (the formal proof is avaiable upon request). Since we already have a interest rate on government bonds, eliminating the interest rate on private bonds can simplify our analysis and notations.
} 
We also assume that investment is irreversible,

$$
I_{j t} \geq 0
$$

To summarize, each firm $j$ solves the static problem (16) and the dynamic programming problem (19) subject to constraints (20), (21), and (22). The sequence of events and information structure can be summarized as follows:

1. The households make labor supply decisions without knowing their idiosyncratic preference shocks $\theta_{t}(i)$.

2. $\theta_{t}(i)$ and $\varepsilon_{t}(i)$ are realized. The households make consumption and saving decisions based on $\theta_{t}(i)$. Firms make their hiring, investment, borrowing/lending, and dividend payment decisions based on $\varepsilon_{t}(i)$.

\subsection{Financial Intermediation}

The financial intermediation in our model is stylized. A representative financial intermediary holds a portfolio consisting of all firms' stocks and collects the aggregate dividends $D_{t}$ from all firms:

$$
D_{t}=\int D_{j t} d j
$$

Although the financial intermediary makes intra-period loans to firms using the dividends, the loans are all repaid within the period, so they do not affect the end-of-period aggregate dividends. The price of such portfolio, $Q_{t}$, is hence

$$
Q_{t}=\rho \frac{\Lambda_{t+1}}{\Lambda_{t}}\left[Q_{t+1}+D_{t+1}\right]
$$

Alternatively, we can also assume that households themselves hold a market portfolio consisting of the stocks of all firms and the equilibrium results will be the same.

\subsection{General Equilibrium}

We denote the aggregate capital stock, aggregate investment, aggregate labor demand, aggregate output, aggregate labor supply, aggregate bond holdings, aggregate household savings, and aggregate consumption in country $\ell$ by $K_{t}^{\ell}=\int_{0}^{1} K_{j t}^{\ell} d j, I_{t}^{\ell}=\int_{0}^{1} I_{j t}^{\ell} d j, N_{t}^{\ell}=\int_{0}^{1} N_{j t}^{\ell} d j, X_{t}^{\ell}=$ $\int_{0}^{1} X_{j t}^{\ell} d j, Y_{t}^{\ell}=\int_{0}^{1} Y_{j t}^{\ell} d j, n_{t}^{\ell}=\int_{0}^{1} n_{i t}^{\ell} d i, S_{t}^{\ell}=\int s_{i t}^{\ell} d i, \tilde{S}_{t}^{\ell}=\int \tilde{s}_{i t}^{\ell} d i$, and $C_{t}^{\ell}=\int_{0}^{1} c_{i t}^{\ell} d i$, respectively. The general equilibrium of the model is defined as the sequences of aggregate variables, $\left\{K_{t}^{\ell}, I_{t}^{\ell}, N_{t}^{\ell}, X_{t}^{\ell}, Y_{t}^{\ell}, n_{t}^{\ell}, S_{t}^{\ell}, \tilde{S}_{t}^{\ell}, C_{t}^{\ell}\right\}$, individual firms' decisions, $\left\{K_{j t}^{\ell}, I_{j t}^{\ell}, N_{j t}^{\ell}, L_{j t}^{\ell}, Y_{j t}^{\ell}\right\}$, individual households' choices, $\left\{a_{i t}^{\ell}, n_{i t}^{\ell}, s_{i t}^{\ell}, \tilde{s}_{i t}^{\ell}, c_{i t}^{\ell}\right\}$, and aggregate prices, $\left\{Q_{t}^{\ell}, W_{t}^{\ell}, R_{k t}^{\ell}, R_{b t}^{\ell}\right\}$, for $\ell \in\{h, f\}$, such 
that each firm or each household solves its optimization problem and all markets (labor, equity, and bonds markets) clear:

$$
\begin{gathered}
N_{t}^{\ell}+X_{t}^{\ell c} \equiv \int_{0}^{1} N_{j t}^{\ell} d j+\int_{0}^{1} X_{j t}^{\ell c} d j=n_{t}^{\ell} \\
\int a_{i t}^{\ell} d i=1 .
\end{gathered}
$$

Notice that in a financial autarky regime, the bond market-clearing condition is $S_{t}^{\ell}=\tilde{S}_{t}^{\ell}=0$, whereas in a financial liberalization regime, the bond market-clearing condition is

$$
S_{t}^{\ell}+\tilde{S}_{t}^{\ell_{c}}=0
$$

where $\tilde{S}_{t}^{\ell}$ denotes country $\ell$ 's holdings of the other country's (foreign) bonds. The aggregate capital stock evolves according to

$$
K_{t+1}^{\ell}=(1-\delta) K_{t}^{\ell}+\int \varepsilon_{j t}^{\ell} I_{j t}^{\ell} d j
$$

\subsection{Solving the General Equilibrium}

Since our model has closed-form solutions for decision rules of both households and firms and the equilibrium distributions of households and firms can be fully characterized by two cutoff variables in each country (with the cutoff variables depending only on aggregate states but not on individual histories, see Appendix A), the general equilibrium of our model can be solved easily in three steps: (i) Solve the decision rules of individual households and firms. (ii) Aggregate the individual decision rules under the law of large numbers to form a system of dynamic nonlinear equations expressed in the aggregate variables. This system of equations is analogous to the first-order conditions and market-clearing conditions in a representative-agent model. And (iii) solve the aggregate policy rules from the nonlinear system of aggregate equations by the standard method used in the existing real-business-cycle literature. To conserve space, we characterize the decision rules and the system of non-linear equations in several propositions in Appendix A and the proofs in Appendix B.

In Appendix A.3 we also show that the aggregate economy exhibits two wedges, a saving wedge and an investment wedge, which create the driving forces of two-way capital flows. The saving wedge is related to the "aggregate" household's intertemporal Euler equation of consumption and saving, and the investment wedge pertains to the "aggregate" firm's investment decisions or Tobin's q. The first wedge generates an excessively low interest rate due to borrowing constraints on the household side that create a motive for precautionary saving and a liquidity premium on bond returns, which push down the financial interest rate on household savings. The second wedge 
generates an excessively high MPK due to borrowing constraints on the firm side that raise the equilibrium Tobin's q. Even though the MPK is very high, firms cannot invest enough because of the borrowing constraints.

\section{International Capital Flows}

Everything else being equal, the directions of international capital flows depend on the differential interest rates and MPKs across countries, which in turn depend on the demand and supply of capital and the degree of financial development in each country. This section characterizes the relationships among the borrowing constraint parameters $\left\{b^{\ell}, \xi^{\ell}\right\}$, the interest rates $\left\{R_{b}^{\ell}\right\}$, and the MPKs $\left\{M P K_{t}^{\ell}\right\}$ for $\ell \in\{h, f\}$ through the lens of demand and supply of capital in each country and explains how they interact to determine the equilibrium interest rate and the MPK.

In the model, both households and firms can save. Households save through bonds and equities (financial assets), whereas firms save through a domestic intra-period loan market (i.e., a corporate union) with participation only from domestic firms. Firms will invest if and only if they find good investment opportunities and will save (remain inactive) otherwise. Because it is costless for firms to borrow from the corporate union (i.e., they pay zero interest for loans), only household savings depend directly on the interest rate in the financial market. In particular, the aggregate household savings depend positively on the interest rate.

Firms' investments are financed by two sources: internal cash flows and outside credit from the corporate union. Borrowing from the corporate union is free but subject to borrowing constraints. ${ }^{28}$ Hence, the aggregate demand for capital depends indirectly on the financial interest rate through the rate of return to equities. When the interest rate is high, the rate of return to equities must also be high to attract equity buyers. This means that either the equity price must be low or the dividend payment must be high. In either case, the present value of a firm's internal cash flows is reduced, which will decrease a firm's investment demand. In addition to this intensive margin, a reduced equity price also raises the threshold (cutoff) of investing, thus lowering the aggregate investment through the extensive margin. Therefore, the aggregate demand for capital depends negatively on the interest rate, among other things.

Thus household savings are channeled to firms only through the equity market and they affect firms' investment demand through equity prices and dividends. When the household saving rate is high, the demand for equities will increase. In equilibrium, either the equity price level will increase or the average dividends will decrease; in either case, the rate of return to equities must

\footnotetext{
${ }^{28}$ Our results do not change if firms must pay interest rate to the corporate union. But this will complicate the problem because we then have two interest rates, one for the household and another for the firms. Also, having an additional interest rate in the private bond market will enhance our results because it will further increase firms' MPK, everything else being equal.
} 
decline. By arbitrage, the interest rate on bonds must also decline. This has positive effects on firms' investment demand because (i) a lower interest rate increases firms' present value of future cash flows due to a lower discount rate, and (ii) a lower dividend payment improves firms' cash positions. A higher rate of investment from firms will then reduce the MPK. This suggests that financial capital inflows from other countries can lower the domestic interest rate and the MPK of the home country. On the other hand, fixed capital inflows from foreign countries will (i) reduce the MPK at home and (ii) lower the domestic interest rate because it reduces the equity return at home.

For the U.S., the inflows of financial capital will decrease the domestic interest rate and the MPK, but meanwhile the outflows of FDI will increase its interest rate and the MPK. Therefore, two-way capital flows have the opposite effects on domestic interest rate and the MPK. This suggests that financial liberalization may not necessarily decrease the U.S. interest rate unless financial capital inflows dominate FDI outflows. On the other hand, the effects of financial development on the interest rate and the MPK are somewhat different from those of capital flows and are more complicated because changes in the borrowing constraints (e.g., $\xi$ ) have ambiguous effects on the interest rate (since they simultaneously shift the demand and supply curves of capital). These effects are studied next.

\subsection{Equilibrium in the Capital Market}

Recall that the market clearing condition for international bonds determines foreign reserves $\tilde{S}^{h}$ at home and $\tilde{S}^{f}$ abroad. From equation (27), we have

$$
\tilde{S}^{h}=-S^{f} \text { and } S^{h}=-\tilde{S}^{f} .
$$

The general equilibrium of the two-country model under financial integration can be characterized by the equilibrium capital-to-output ratios $\left\{\frac{\bar{K}^{h}}{Y^{h}}, \frac{\bar{K}^{f}}{Y^{f}}\right\}$ and the real interest rates $\left\{R_{b}^{h}, R_{b}^{f}\right\}$, which are determined jointly by the demand and supply of capital in the two countries (see Appendix A). ${ }^{29}$

However, to understand the factors determining the rates of return to capital and the directions of capital flows, it helps to study a world without any form of international capital flows - the financial autarky regime. To obtain a financial autarky regime, we can simply set the cost parameters $\gamma_{k}$ and $\gamma_{s}$ to infinity so that there are no cross-border flows of financial and fixed capital (i.e., $u^{\ell}=S^{\ell}=\tilde{S}^{\ell}=0$ ). In a financial autarky equilibrium, the demand function (70) and supply function (72) of capital in Appendix A.4 for the two countries collapse to

\footnotetext{
${ }^{29} \bar{K}^{\ell}$ denotes total capital (domestic and foreign) utilized in production in country $\ell$, which includes both domestic capital and FDI.
} 


$$
\begin{gathered}
\alpha \frac{Y^{\ell}}{K^{\ell}}=\mathbb{R}\left(R_{b}^{\ell}, \xi^{\ell}\right) \\
(1-\alpha) \frac{Y^{\ell}}{K^{\ell}}=\left[\Upsilon\left(R_{b}^{\ell}\right)-R_{b}^{\ell}+1\right] \mathbb{Q}\left(R_{b}^{\ell}, \xi^{\ell}\right)+\Upsilon\left(R_{b}^{\ell}\right) \mathbb{Q}\left(R_{b}^{\ell}, \xi^{\ell}\right) b^{\ell},
\end{gathered}
$$

where $\frac{\partial \mathbb{R}\left(R_{b}^{\ell}, \xi^{\ell}\right)}{\partial R_{b}^{\ell}}>0, \frac{\partial \mathbb{R}\left(R_{b}^{\ell}, \xi^{\ell}\right)}{\partial \xi^{\ell}}<0, \Upsilon^{\prime}\left(R_{b}^{\ell}\right)<0, \frac{\partial \mathbb{Q}\left(R_{b}^{\ell}, \xi^{\ell}\right)}{\partial R_{b}^{\ell}}<0$ and $\frac{\partial \mathbb{Q}\left(R_{b}^{\ell}, \xi^{\ell}\right)}{\partial \xi^{\ell}}$, for $\ell=\{h, f\}$. Note that due to the immobility of both fixed and financial capital, there is no interaction between the two countries, and the equilibrium capital-to-output ratio and interest rate in each country are then fully pinned down by the domestic capital demand curve and domestic capital supply curve in equations (30) and (31).

Proposition 1 In the financial autarky regime, the country with tighter borrowing constraints on the firm side (i.e., smaller $\xi$ ) has a higher MPK but either a higher or a lower domestic interest rate; and the country with tighter borrowing constraints on the household side (i.e., smaller b) has both a lower MPK and a lower real interest rate.

The proof is straightforward and is illustrated graphically in Figure 5. The left panel is the autarky equilibrium in which the two countries differ only in the tightness of borrowing constraints on the firm side, but they have the same tightness of borrowing constraints on the household side. Suppose firms in country $f$ can borrow more than firms in country $h: \xi^{f}>\xi^{h}$. The "S-S" curve represents capital supply and the "D-D" curve capital demand, and point $H$ represents autarky equilibrium in country $h$ and point $F$ autarky equilibrium in country $f$. According to equations (30) and (31), a larger $\xi$ will shift both the demand and the supply curves towards the right. As a result, point $H$ will lie to the left side of point $F$ and the home country will have a lower capitalto-output ratio (or a higher MPK). The rank of interest rates in the two countries, however, is ambiguous since point $F$ can be either above or below point $H$, depending on the magnitudes of the right-ward shifts of the two curves. The intuition is that looser borrowing constraints on firms in the foreign country lead to a higher demand for capital, which shifts out the "D-D" demand curve directly and results in a lower Tobin's $q$ due to the lowered MPK. A lower Tobin's $q$ in turn leads to a lower equity price $(Q)$. Thus, households are willing to buy more equities or, equivalently, save more. As a result, the "S-S" supply curve will also shifts out to the right. Consequently, whether the equilibrium interest rate is lower or higher than that in country $h$ is ambiguous.

The right panel in Figure 5 illustrates the case in which the tightness of borrowing constraint is identical on the firm side between the two countries but differs on the household side. Assume households in country $f$ are less borrowing constrained, i.e., $b^{f}<b^{h}$. From equation (30), the two countries have thus identical capital demand since $\xi^{h}=\xi^{f}$, but the capital supply curve in 
the foreign country lies to the left of the home country's. This occurs because households in the foreign country tend to borrow more and save less due to a less constrained borrowing limit. In equilibrium, the foreign country (point $F$ ) ends up with both a higher interest rate and a higher MPK (lower capital-to-output ratio) than the home country (point $H$ ).
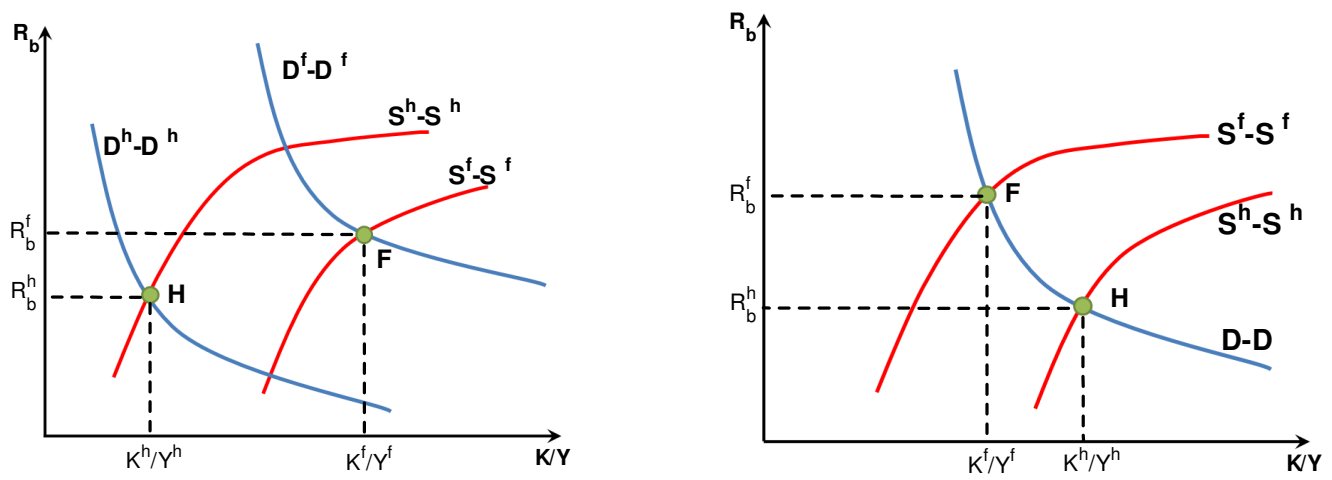

Figure 5. Steady-State Equilibrium in Financial Autarky

This result shows that LDCs could have both a lower interest rate and a lower MPK than developed countries. Consequently, both financial capital and fixed capital should flow from South to North. Although such a one-way unidirectional capital flow is observed in the real world for some developing countries (such as the oil-exporting countries in the Middle East), it is not the dominant pattern of international capital flows. Hence, explaining the two-way capital flow puzzle requires borrowing constraints on both the household side and the firm side.

\subsection{Two-Way Capital Flows}

Proposition 2 Moving from financial autarky to financial liberalization (i.e., $\gamma_{k}<\infty$ and $\gamma_{s}<$ $\infty)$, financial capital will flow from country $h$ to country $f$ and fixed capital (FDI) will flow in the opposite direction simultaneously if one of the following sets of conditions are satisfied: (i) $\xi^{h}<\xi^{f}$ and $\underline{b}\left(\xi^{f}, \xi^{h}, b^{f}\right)<b^{h}<\bar{b}\left(\xi^{f}, \xi^{h}, b^{f}\right)$, or $(i i) b^{h}<b^{f}$ and $\xi^{h}<\underline{\xi}\left(\xi^{f}, b^{h}, b^{f}\right)$, provided that $\varepsilon_{j t}$ is Pareto distributed.

Proof. See Appendix A.5.

As discussed before (see Figure 5), the assumption of $\xi^{h}<\xi^{f}$ alone guarantees that the home country has a higher MPK in autarky and thus it would attract FDI from abroad. However, the direction of financial capital flow is ambiguous in this case because the autarky interest rate at home can be either lower or higher than the foreign interest rate. Therefore, to ensure a lower interest rate at home, the household side must also face a tight enough borrowing constraint $\left(b^{h}<\bar{b}\right)$. 
However, since a tighter borrowing constraint on the household side also lowers the MPK at home, the value of $b^{h}$ cannot be too low (i.e., $b^{h}>\underline{b}$ ). This explains the first set of conditions in the proposition.

On the other hand, the assumption of $b^{h}<b^{f}$ alone ensures that the home country has both a lower interest rate and a lower MPK, so we also need a tight enough borrowing constraint on the firm side at home (or a loose enough borrowing constraint abroad) to induce a higher MPK at home than abroad. However, although a lower $\xi^{h}$ at home induces a higher MPK, its effect on the interest rate $R_{b}^{h}$ is ambiguous. Therefore, we do not know if the home country will necessarily have a lower interest rate if $\xi^{h}$ is reduced. One special case is that if $\varepsilon$ follows the Pareto distribution, then the interest rate depends only on $b^{\ell}$, so the value of $\xi^{\ell}$ does not affect the interest rate. This explains the second set of conditions in the proposition.

These important conditions required in the above proposition to generate the two-way capital flows explain why we do not always observe two-way capital flows between developing and developed countries. For example, among the 22 emerging markets studied in Section 2, two of them do not have negative position in net FDI asset (FDI inflow), and only 15 of them present net financial capital outflow starting from 2000. Also, for the group of 21 developed countries, only 16 of them exhibit the two-way capital flow pattern, although the group as a whole presents very significant two-way pattern-i.e., financial capital inflow and FDI outflow.

FDI and financial capital flows tend to reinforce each other in the opposite directions through their general-equilibrium effects on the interest rate and MPK. Specifically, FDI flows from $f$ to $h$ tend to drive out $h$ 's financial capital because inward FDI lowers the domestic interest rate; and bond flows from $h$ to $f$ tend to drive out fixed capital in $f$ toward $h$ because inward financial capital flows brings down $f^{\prime}$ 's MPK. Therefore, the parameter requirements on the values of $\left\{\xi^{\ell}, b^{\ell}\right\}$ for triggering two-way capital flows are easier to satisfy than they appear to be in Proposition 2.

\subsection{Balance of Payments}

Persistent net capital inflows would imply a current account deficit in the short run but a trade surplus in the long run because of positive interest payments in the steady state. ${ }^{30}$ Since conventional wisdom has it that unidirectional one-way capital flow is not sustainable (i.e., a country's net foreign asset position should be zero in steady state), trade should always be balanced in the

\footnotetext{
${ }^{30}$ Following MQR (2009), a nation's current account balance $\left(C A_{t}\right)$ is defined as the net changes in foreign asset positions $\left(N F A_{t}\right)$ :

$$
C A_{t}=N F A_{t}-N F A_{t-1}
$$

which is zero in the steady state. Since the current account equals net exports $\left(N X_{t}\right)$ plus net factor payments $\left(r_{t} N F A_{t}\right)$, where $r$ denotes the rate of return, we have in the steady state $N X=-r N F A$. Thus, if the country has a negative foreign asset position because of capital inflows $(N F A<0)$, it runs a trade surplus in the steady state.
} 
long run. ${ }^{31}$ However, if financial capital (e.g., bonds) and fixed capital (FDI) earn different rates of return and they flow in the opposite directions, a country can sustain a long-run trade deficit (or a long-run surplus) even if its net capital (financial and fixed) inflows are balanced at zero and there is no long-run growth. For example, if the U.S. gleans a substantially larger rate of return from foreign capital than foreign investors do from owning U.S. capital (as in the data), it could run substantial trade deficits forever. Conversely, if China holds most of the world's low-yield foreign reserves and pays the highest rate of return to FDI inflows from rich countries, it will experience a trade surplus even in the long run. ${ }^{32}$

The two forms of capital flows have the opposite effects on the domestic interest rate. Therefore, it is not clear a priori that financial capital inflows from the South would necessarily reduce the interest rate in the North because FDI outflows will raise it through a higher MPK in the North. In addition, these two forms of capital flows reinforce each other through general equilibrium effects on the interest rate. For example, FDI inflows may crowd out domestic fixed capital investment in the recipient country and push down the real interest rate, which in turn can trigger financial capital outflows. This in turn may restore the interest rate to its original level. On the other hand, financial capital inflows reduce the real interest rate and the MPK in the recipient country, thus causing FDI outflows, which in turn raises the interest rate.

The balance of payments is straightforward to compute in our model. For bond flows we have $S_{t}^{h}=-\tilde{S}_{t}^{f}$ and $\tilde{S}_{t}^{h}=-S_{t}^{h}$. Moreover, either $S_{t}^{h}>0$ or $\tilde{S}_{t}^{h}>0$, but not both. For fixed capital flows, only one of the following conditions is true: either $u_{t}^{h}>0$ or $u_{t}^{f}>0$, but not both. Suppose $\tilde{S}_{t}^{h}>0$ and $u_{t}^{f}>0$ (as in the data). The current account balance of the home country $\left(C A_{t}^{h}\right)$ in period $t$ is then given by

$$
C A_{t}^{h}=\left[\tilde{S}_{t+1}^{h}-\tilde{S}_{t}^{h}\right]-\left[u_{t}^{f} K_{t}^{f}-u_{t-1}^{f} K_{t-1}^{f}\right]
$$

where the terms inside the first bracket are the changes in financial asset positions and those in the second bracket are the changes in nonfinancial asset (FDI) positions. The net factor payments $\left(N F P_{t}^{h}\right)$ from abroad to the home country are given by

$$
N F P_{t}^{h}=\left[R_{b t-1}^{f} \tilde{S}_{t}^{h}-\tilde{S}_{t}^{h}\right]-r_{t}^{h} u_{t}^{f} K_{t}^{f}
$$

where the terms inside the square bracket on the RHS are the interest rate payments from abroad and the second term on the RHS is the home country's net income payments (rents) to foreign firms for their FDI. The trade balance of the home country $\left(T B_{t}^{h}\right)$ can be obtained from the following

\footnotetext{
${ }^{31}$ Chien and Naknoi (2011) show that this is no longer the case if long-run growth is introduced.

${ }^{32}$ See Chien and Naknoi (2011) for more discussions on this issue when long-run growth is involved.
} 
accounting identity: ${ }^{33}$

$$
T B_{t}^{h}=C A_{t}^{h}-N F P_{t}^{h}
$$

\section{Quantitative Analysis}

\subsection{Calibration}

We now calibrate the parameters in the model by taking China as the home country $h$ and the U.S. as the foreign country $f$. The time period is one quarter. In our dynamic analysis, we set the initial period (before the financial liberalization) to 1992Q1. We partition the model parameters into three sets. The first set $\Theta_{1}=\left\{\alpha, \beta, \delta, \psi^{\ell}\right\}$ contains standard parameters and we assume they take common values across countries, with the exception of $\psi$ which is country-specific. The second set $\Theta_{2}$ contains the financial friction parameters and those pertaining to the distributions of idiosyncratic shocks. This parameter set determines the wedges in asset returns. The third set $\Theta_{3}$ contains parameters pertaining to international transaction costs in capital flows. This parameter set determines the speed and scope of international capital flows given the wedges in asset returns.

To calibrate $\Theta_{1}$, we follow the standard business cycle literature (e.g. King and Rebelo, 1999) to set the discounting factor $\beta$ to 0.985 , the capital share $\alpha$ to 0.36 and depreciation rate $\delta$ to 0.025 . We set the value of $\psi$ such that the implied steady-state fraction of hours worked is $1 / 3$ in each country. Since different countries have different levels of steady-state output and consumption, the implied value of $\psi$ is thus different for China and the U.S.

The second set $\Theta_{2}$ contains country-specific financial friction parameters. We calibrate their values by matching the model-implied moments in the financial autarky equilibrium to the counterparts in real data (e.g., in the period 1980-1991, long before China joining the WTO). We assume that the idiosyncratic investment efficiency shock $\varepsilon$ and preference shock $\theta$ follow Pareto distributions with the cumulative probability distribution $(\mathrm{CDF}) 1-\left(\varepsilon / \varepsilon_{\min }^{\ell}\right)^{-\sigma^{\ell}}$ and $1-\left(\theta / \theta_{\min }^{\ell}\right)^{-\eta^{\ell}}$ and the mean $\mu_{\varepsilon}^{\ell}=\frac{\sigma^{\ell}}{\sigma^{\ell}-1} \varepsilon_{\min }^{\ell}$ and $\mu_{\theta}^{\ell}=\frac{\eta^{\ell}}{\eta^{\ell}-1} \theta_{\min }^{\ell}$, respectively. Note that the variance of the distribution reinforces financial frictions by affecting the precautionary saving motives of households and firms' investment rates. Given the distribution functions, the second parameter set is then given by $\Theta_{2}=\left\{b^{\ell}, \xi^{\ell}, \sigma^{\ell}, \mu_{\varepsilon}^{\ell}, \eta^{\ell}, \mu_{\theta}^{\ell}\right\}, \ell \in\{h, f\}$. Given that $\mu_{\theta}$ is redundant once the other parameters are fixed, we normalize $\mu_{\theta}=1$ for both countries. The first two parameters pertain to borrowing

${ }^{33}$ To be precise, aggregating the individual budget constraint in the home country gives

$$
\left(\tilde{S}_{t+1}^{h}-\tilde{S}_{t}^{h}\right)-\left(u_{t}^{f} K_{t}^{f}-u_{t-1}^{f} K_{t-1}^{f}\right)=Y_{t}^{h}-\left(C_{t}^{h}+\hat{I}_{t}^{h}\right)+\left(R_{b t-1}^{f} \tilde{S}_{t}^{h}-\tilde{S}_{t}^{h}\right)-r_{t}^{h} u_{t}^{f} K_{t}^{f}
$$

where $\hat{I}_{t}^{h}$ is the total domestic investment including investments from both domestic firms and foreign firms and the cross-border adjustment costs. The trade balance is thus $Y_{t}^{h}-\left(C_{t}^{h}+\hat{I}_{t}^{h}\right)=C A_{t}^{h}-N F P_{t}^{h}$. 
limits, and we calibrate them based on household and firm finance data (if available). Specifically, for the U.S. economy, $b^{f}$ captures the financial tightness on the household side. According to our model specification, in the autarky equilibrium $b^{f}$ is defined as the ratio of the household borrowing to the value of equity, $\frac{s_{i t}+Q_{t}}{Q_{t}}$. It also reflects the change in household debt relative to the change in the value of equity, i.e., $\frac{\Delta \text { Household Debt }}{\Delta \text { Household Equity }}$. According to the findings in Mian and Sufi (2011), U.S. households borrowed 25 cents on every dollar of additional home equity value in 1997, we then set $b^{f}$ to 0.25 . In the sensitivity analysis, we will re-calibrate $b^{f}$ according to other household finance surveys, and show that the results are quite robust. The parameter in the firm's borrowing constraint $\xi^{f}$ is defined as $\frac{L_{j t}}{Q_{j t}}$ (or $\frac{\Delta \text { Loan }}{\Delta \text { Equity }}$ ). According to the U.S. firm-level evidences in Covas and Den Haan (2011), the average ratio of the change in firm's liability to the change of firm's value of asset is $62 \%$, so we set $\xi^{f}=0.62$. For China, we do not have reliable information about its household debt and firm debt to pin down $\left\{b^{h}, \xi^{h}\right\}$. So instead we use $\left\{b^{h}, \xi^{h}\right\}$ to target the financial development gap - the gap between the two debt-to-output rations in China and U.S., as shown in Figure 3. Our model is not able to generate a high enough debt-to-GDP ratio for either country under any parameter values, but we can match the average gap between these ratios across the two countries shown in Figure $3 .^{34}$ Given that we have two parameters to match just one moment, we set one of the parameters arbitrarily, e.g., we let $b^{h}$ be equal to a reasonable fraction (e.g., 1/2) of its U.S. counterpart $b^{f}$. We will show in Appendix D that our results are not sensitive to such values.

Table 2. Targeted Aggregate Moments

\begin{tabular}{lrrrr}
\hline \hline & \multicolumn{2}{c}{ Home (China) } & \multicolumn{2}{c}{ Foreign (U.S.) } \\
\hline \multirow{2}{*}{ Saving rate } & Data & Model & Data & Model \\
MPK & 0.40 & 0.40 & 0.18 & 0.18 \\
Real interest rate & $22 \%$ & $22 \%$ & $11 \%$ & $11 \%$ \\
& $-0.71 \%$ & $-0.71 \%$ & $6 \%$ & $6 \%$ \\
U.S. Credit-to-GDP Ratio & Data & \multicolumn{2}{c}{ Model } \\
China Credit-to-GDP Ratio & \multicolumn{2}{c}{1.5} & \multicolumn{2}{c}{1.5} \\
\hline
\end{tabular}

The remaining three parameters in $\Theta_{2},\left\{\sigma, \mu_{\varepsilon}, \eta\right\}$ pertain to the distributions of idiosyncratic shocks. We use three important data moments to pin them down: the aggregate saving rate, the MPK, and the risk-adjusted real interest rate in each country. We can show that a country's interest rate $\left(R_{b}\right)$, the $M P K$ and the saving rate $(S R)$ under an autarky regime are jointly determined by

\footnotetext{
${ }^{34}$ As discussed in the previous sections, it is the gap between the Home and Foreign countries that matters for the two-way capital flows, not the absolute level of total debt-to-GDP ratio in a country.
} 
the following three equations

$$
\begin{aligned}
R_{b} & =\frac{\delta(\sigma-1)}{\sigma}\left(\frac{\alpha}{S R}-1\right)+1, \\
M P K & =\delta\left[\frac{\xi}{\delta} \frac{\sigma}{(\sigma-1)}+\frac{\alpha}{S R}\right]^{-\frac{1}{\sigma}} \frac{1}{S R} \frac{1}{\mu_{\varepsilon}}-\delta, \\
S R & =\left[\frac{\sigma(b+1)}{\delta(\sigma-1)} \frac{\Xi\left(R_{b}, \eta\right)}{1-\Xi\left(R_{b}, \eta\right)}+1\right]^{-1} .
\end{aligned}
$$

where $\Xi\left(R_{b}, \eta\right)=(\eta-1)^{\frac{1}{\eta}-1}\left[\frac{1}{\beta R_{b}}-1\right]^{\frac{1}{\eta}}-\left[\frac{1}{\beta R_{b}}-1\right]$. These equations show that: (i) Given the saving rate $S R$, equation (35) pins down the parameter $\sigma$; (ii) Given the $M P K, S R$ and $\sigma$, equation (36) pins down the parameter $\mu_{\varepsilon}$; (iii) Given $S R, R_{b}$ and $\sigma$, equation (37) pins down $\eta$. So we can calibrate the three parameters $\left\{\sigma, \mu_{\varepsilon}, \eta\right\}$ jointly to match the three moments (i.e., average $R_{b}$, MPK and $S R$ ) in the 1980-1991 period separately for the U.S. and China (see Table 2).

The third parameter set $\Theta_{3}$ is related to the transaction costs of international capital flows. In the model, we specify the cross-border transaction costs for FDI and bonds as $\gamma_{k} \frac{u_{j t}^{1+\chi}}{1+\chi} K_{j t}$ and $\gamma_{s} \frac{s_{i t}^{1+\tau}}{1+\tau}$, respectively. For simplicity, we assume that the transaction costs are quadratic, i.e., $\chi=\tau=1$. The parameters $\left\{\gamma_{k}, \gamma_{s}\right\}$ control the magnitudes of FDI flows and bond flows, therefore they represent the extent of financial liberalization. To capture the gradualness of international market integration, we assume that $\gamma_{k}$ and $\gamma_{s}$ are time-varying following deterministic $\operatorname{AR}(1)$ processes:

$$
\begin{aligned}
& \gamma_{k t}-\bar{\gamma}_{k}=\rho_{k}\left(\gamma_{k t-1}-\bar{\gamma}_{k}\right), \text { given } \gamma_{k 0}, \\
& \gamma_{s t}-\bar{\gamma}_{s}=\rho_{s}\left(\gamma_{s t-1}-\bar{\gamma}_{s}\right), \text { given } \gamma_{s 0}
\end{aligned}
$$

The processes of $\gamma_{k t}$ and $\gamma_{s t}$ start with some initial values and gradually achieve their long-run values $\bar{\gamma}_{k}$ and $\bar{\gamma}_{s}$. So the third set of parameters are given by $\Theta_{3} \equiv\left\{\gamma_{k 0}, \gamma_{s 0}, \bar{\gamma}_{k}, \bar{\gamma}_{s}, \rho_{k}, \rho_{s}\right\}$, which are calibrated to minimize the distance between model-simulated paths and actual paths of capital flows in the home country (China). In particular, the targeted series are Chinese net inward FDI position-to-GDP $\left(F D I_{t}\right)$ and total financial asset position-to-GDP $\left(S_{t}\right)$ from 1992 to $2010 .{ }^{35}$ The parameters are chosen to solve the following minimization problem

$$
\hat{\Theta}_{3}=\arg \min _{\Theta_{3}}\left[\begin{array}{c}
F D I_{t}^{\text {model }}-F D I_{t}^{\text {Data }} \\
S_{t}^{\text {model }}-S_{t}^{\text {Data }}
\end{array}\right]^{\prime} \hat{W}\left[\begin{array}{c}
F D I_{t}^{\text {model }}-F D I_{t}^{\text {Data }} \\
S_{t}^{\text {model }}-S_{t}^{\text {Data }}
\end{array}\right] .
$$

For simplicity, the weighting matrix $\hat{W}$ is an identity matrix. Table 3 summarizes all the calibrated parameter values.

\footnotetext{
${ }^{35}$ The data series are calculated from the updated dataset of Lane and Milesi-Ferretti (2007).
} 
Table 3. Deep Parameter Values

\begin{tabular}{|c|c|c|c|}
\hline & & Home (China) & Foreign (U.S.) \\
\hline$\beta$ & discounting factor & 0.985 & 0.985 \\
\hline$\alpha$ & capital share in production & 0.36 & 0.36 \\
\hline$\delta$ & capital depreciation rate & 0.025 & 0.025 \\
\hline$\xi$ & borrowing constraint for firm & 0.006 & 0.62 \\
\hline$b$ & borrowing constraint for household & 0.125 & 0.25 \\
\hline$\sigma$ & shape parameter of $\varepsilon$ & 3.45 & 2.42 \\
\hline$\mu_{\varepsilon}$ & mean of $\varepsilon$ & 0.26 & 0.20 \\
\hline$\eta$ & shape parameter $\theta$ & 1.14 & 2.05 \\
\hline$\mu_{\theta}$ & mean of $\theta$ & 1 & 1 \\
\hline$\psi$ & coefficient of leisure & 1.87 & 2.32 \\
\hline \multicolumn{4}{|c|}{ International Capital Flow Parameters } \\
\hline & \multicolumn{3}{|c|}{ A. FDI Trans. Cost: $\gamma_{k t} \frac{u_{j t}^{1+\chi}}{1+\chi} K_{j t}$} \\
\hline $\bar{\gamma}_{k}$ & steady-state value in liberalization & \multicolumn{2}{|c|}{0.30} \\
\hline$\gamma_{k 0}$ & initial value of $\gamma_{k t}$ & \multicolumn{2}{|c|}{4.60} \\
\hline$\chi$ & curvature & \multicolumn{2}{|c|}{1} \\
\hline$\rho_{k}$ & $\operatorname{AR}(1)$ coefficient of $\gamma_{k t}$ process & \multicolumn{2}{|c|}{0.83} \\
\hline & \multicolumn{3}{|c|}{ B. Financial Capital Trans. Cost: $\gamma_{s t} \frac{s_{i t}^{1+\tau}}{1+\tau}$} \\
\hline $\bar{\gamma}_{s}$ & \multicolumn{2}{|c|}{ steady-state value in liberalization } & 0.44 \\
\hline$\gamma_{s 0}$ & initial value of $\bar{\gamma}_{s t}$ & \multicolumn{2}{|c|}{0.01} \\
\hline$\tau$ & curvature & \multicolumn{2}{|c|}{1} \\
\hline$\rho_{s}$ & $\operatorname{AR}(1)$ coefficient of $\gamma_{s t}$ process & \multicolumn{2}{|c|}{0.92} \\
\hline
\end{tabular}

\subsection{Steady-State Predictions}

Table 4 reports the predictions of the model under the financial autarky and liberalization regimes. Columns 1 and 2 pertain to China and the ROW (represented by the U.S.) in the autarky regime. Columns 3 to 8 pertain to the two countries in the financial liberalization regime (with partial and full liberalization, respectively).

In the autarky regime, China has a higher Tobin's $q$ than the U.S. (4.99 vs 1.79), a higher annual rate of return to fixed capital ( $22 \%$ vs $11 \%)$, but a lower interest rate $(-0.71 \%$ vs $6.0 \%)$. All these gaps are predicted by our model because of the gaps in financial development between China and the U.S. ${ }^{36}$

\footnotetext{
${ }^{36}$ Due to the modelling strategy we choose to simplify computations, the notion of debt in our model corresponds only to short-term debts, including the one-period government bond on the household side and the intra-period debt on the firm side. Hence, it makes sense to compare our model's prediction only with the short-term debt in the data. In our benchmark calibration, the model's prediction for the debt-to-GDP ratio in the U.S. economy is $18 \%$, while for China it is $12 \%$. Based on the U.S. flow of funds data, the short-term debt-to-GDP ratio is around 27\%. For Chinese economy, the People's Bank of China reports the short-term loans each year. However, in China the major part of debt goes to state-owned enterprises (SOEs) because of the lack of sufficiently developed private banking system and private bond market for firms to issue debt (consistent with our model); thus most credit loans are channeled by the state-owned banking system and the bulk of such loans goes to the SOEs. In 2013 the total debt-to-GDP ratio for SOEs was around $103 \%$, while the domestic credit-to-GDP ratio (according to WDI) was around $140 \%$. That is, the debt borrowed by SOEs accounts at least $70 \%$ of the overall total debt in China. If we assume that the fraction of
} 
Because of the cross-country spread in the rates of return to financial and fixed capital, financial liberalization between countries will induce China to hold negative foreign productive asset positions (FDI inflow) but positive financial asset positions (bond outflow), with the former equal to $-19.85 \%$ of GDP and the latter equal to $53.06 \%$ of GDP in the long-run steady state. The model-implied net FDI position is close to the actual value, while the financial asset position is about $15 \%$ higher than that in the data, ${ }^{37}$ indicating that the Chinese economy may not actually be in its steady state yet in the financial liberalization regime.

Table 4. Steady States in Financial Autarky and Financial Liberalization

\begin{tabular}{|c|c|c|c|c|c|c|c|c|}
\hline & \multirow{2}{*}{\multicolumn{2}{|c|}{ Autarky }} & \multirow{2}{*}{\multicolumn{2}{|c|}{$\begin{array}{l}\text { Only Financial } \\
\text { Capital Flows }\end{array}$}} & \multirow{2}{*}{\multicolumn{2}{|c|}{$\begin{array}{c}\text { Only Fixed } \\
\text { Capital Flows }\end{array}$}} & \multirow{2}{*}{\multicolumn{2}{|c|}{$\begin{array}{c}\text { Both } \\
\text { Capital Flows }\end{array}$}} \\
\hline & & & & & & & & \\
\hline & (1) & $(2)$ & (3) & (4) & $(5)$ & $(6)$ & (7) & (8) \\
\hline & China & ROW & China & ROW & China & ROW & China & ROW \\
\hline Rate of return to fixed K (MPK) (\%) & 22.00 & 11.00 & 22.62 & 10.94 & 20.22 & 11.05 & 20.64 & 11.01 \\
\hline Real interest rate (\%) & -0.71 & 6.00 & -0.55 & 5.96 & -1.15 & 6.03 & -1.05 & 5.99 \\
\hline Tobin's $q$ & 4.99 & 1.79 & 4.96 & 1.79 & 5.07 & 1.79 & 5.05 & 1.79 \\
\hline Net foreign asset positions (\%GDP) & $\ldots$ & .. & 52.33 & -38.26 & -17.39 & 14.78 & 33.21 & -26.28 \\
\hline Direct investment abroad (\%GDP) & $\cdots$ & $\cdots$ & $\cdots$ & $\cdots$ & -17.39 & 14.78 & -19.85 & 15.71 \\
\hline Bonds (\%GDP) & $\cdots$ & $\cdots$ & 52.33 & -38.26 & $\cdots$ & $\cdots$ & 53.06 & -41.99 \\
\hline Trade imbalances (\%GDP) & $\cdots$ & $\cdots$ & -3.05 & 2.23 & 5.25 & -4.47 & 2.97 & -2.35 \\
\hline Interest rate payments (\%GDP) & $\cdots$ & ... & -3.05 & 2.23 & $\cdots$ & ‥ & 3.12 & -2.47 \\
\hline
\end{tabular}

To better understand the different impacts of financial and fixed capital flows on each country's MPK and interest rate, we consider first the partial liberalization scenario by allowing only one type of capital (bonds or fixed capital) to move across borders. Columns 3 and 4 report the steady state in which only financial assets (bonds) are internationally mobile. The opening up of bond markets induces financial capital outflow from China to the ROW, which makes the interest rates converge somewhat across countries - the convergence is not high because of transaction costs in international capital flows (or home bias). As a result, the equilibrium real interest rate in China increases from $-0.71 \%$ in autarky to $-0.55 \%$, which further raises the domestic rate of return to fixed capital from $22 \%$ to $22.62 \%$. The situation in the ROW is the opposite: The real interest rate decreases slightly from $6.0 \%$ in autarky to $5.96 \%$, and the MPK declines from $11 \%$ in autarky to $10.94 \%$. These results confirm our previous discussions that international financial asset flows narrow the gap in country-specific interest rates but enlarge the gap in the rate of return to fixed capital.

SOEs' short-term debt in total short-term debt is the same as the that of the total debt, then the short-term debt to non-SOEs is around $15 \%$ of China's GDP, closely matching our model's predictions (12\%). So our model can explain about $80 \%$ of China's short-term debt and $70 \%$ of US short-term debt.

The most important thing to notice, however, is that it is the relative gap of financial development (debt-to-GDP ratio) between China and the US that matters for our results, not the absolute level of debt-to-GDP ratio in each country when it comes to international capital flows. This is why in the calibration we do not particularly target the absolute country-specific debt-to-GDP ratio, but only the gap between the two countries' debt-to-GDP ratios.

${ }^{37}$ By 2010 , the accumulative net inward FDI of China was about $21 \%$ of GDP, and the net outward debt position was about $46 \%$ of GDP. 
Columns 5 and 6 report the situation when only fixed capital can move internationally. Fixed capital will flow from the ROW to China because China has a higher MPK in autarky. In particular, FDI inflows increase the capital supply in China, thereby reducing China's domestic interest rate from $-0.71 \%$ to $-1.15 \%$. The inward FDI flow also reduces the equilibrium MPK in China from $22 \%$ to $20.22 \%$. In contrast, FDI outflows raise the interest rate in the ROW from $6.0 \%$ in autarky to $6.03 \%$, and pushes up ROW's MPK from $11 \%$ to $11.05 \%$.

The outcome with both types of capital flows are reported in columns 7 and 8 . Note that neither MPK nor the interest rate changes significantly from their autarky values. These predictions are consistent with the data in Figure 2 where the gaps in MPKs and risk-adjusted real interest rates remain roughly constant over time (e.g., both before and after China joined the WTO in 2001). Our model is consistent with this fact despite the fact that financial liberalization in our model can trigger enormous amount of capital flows in the steady state. The reasons may be as follows. On the data part, China has capital controls and an essentially fixed (or managed floating) exchange rate with the U.S. dollar. Hence, the interest rates in the two countries are never equalized. Thus, small wonder that they still show significant differences even today. ${ }^{38}$ This persistent interest rate gap as well as the persistent gap in MPK are captured in our model by the international transaction costs. Therefore, despite the large two-way capital flows across countries, the gaps between the two countries' asset returns are not significantly reduced. In other words, our quantitative analysis shows that China's saving glut does not significantly reduce the real interest rate in the U.S. when our model is calibrated to match the actual amount of financial capital outflows from China to the U.S.

Financial capital outflow tends to increase the domestic interest rate and fixed capital return, whereas FDI inflow has the opposite effect. Since international capital flows are fully determined by the cross-country discrepancies in interest rate and MPK, the two types of capital flows reinforce each other-FDI inflows may cause financial capital outflows, and financial capital outflows in turn may cause FDI inflows. The middle panel in Table 4 labeled "Net foreign asset positions" quantitatively illustrates this point. When only bonds can be traded across countries, the financial capital outflow from China is $52.33 \%$ of its GDP. When only fixed capital is allowed to move across countries, FDI inflows to China is $17.39 \%$ of its GDP. The corresponding ratios increase significantly when the two capital markets are both liberalized. The financial capital outflows from China become $53.06 \%$ of its GDP, rising 0.73 percentage points in GDP share compared to the value in partial liberalization. Meanwhile, the FDI inflows rise to $19.85 \%$ of China's GDP, which is more than 2.4 percentage points higher in its GDP share.

The bottom panel in Table 4 reports the impact of capital flows on trade balances. When only

\footnotetext{
${ }^{38}$ Figure $2 \mathrm{~B}$ shows a temporary convergence between the two interest rates in 2004 but they diverged again after that.
} 
financial assets are mobile across countries, China will run a trade deficit (-3.05\% of GDP) in the long run. In contrast, the U.S. (representing the ROW) will run a trade surplus (2.23\% of GDP). These trade imbalances come entirely from interest payments on international bonds. However, when only fixed capital is mobile across countries, China will run a trade surplus (5.25\% of GDP) in the steady state while ROW will run trade deficits ( $-4.47 \%$ of GDP). These balances come entirely from capital gains from FDI positions (i.e., net FDI outflows from ROW to China). Because the rate of return to FDI dominates the rate of return to financial assets, in the full liberalization regime China will maintain a long-run trade surplus of $2.97 \%$ of its GDP while ROW (e.g., the U.S.) will maintain a trade deficit of $-2.35 \%$ of its GDP. Therefore, even though FDI flows are smaller than financial asset flows in GDP shares (both in the data and in the model), developed countries can have permanent trade deficits with developing countries because FDI payments from developing countries are much larger than interest payments on bonds from developed countries.

\subsection{Transitional Dynamics}

Figure 6 shows the transitional dynamics of major aggregate variables when the model economy opens up from financial autarky to financial liberalization (with both financial and fixed capital flows). The figure shows a typical pattern of diverging trends in two-way capital flows: financial assets leave China and flow into the ROW (red line in the second panel on the left column), while FDI leaves the ROW and flows into China (red line in the top panel on the right column). Because the volume of financial asset flows dominates that of FDI flows, the net foreign asset position is positive in China and negative in the ROW after about nine years (top left panel), explaining the reverse capital flow pattern discussed in the Introduction. 

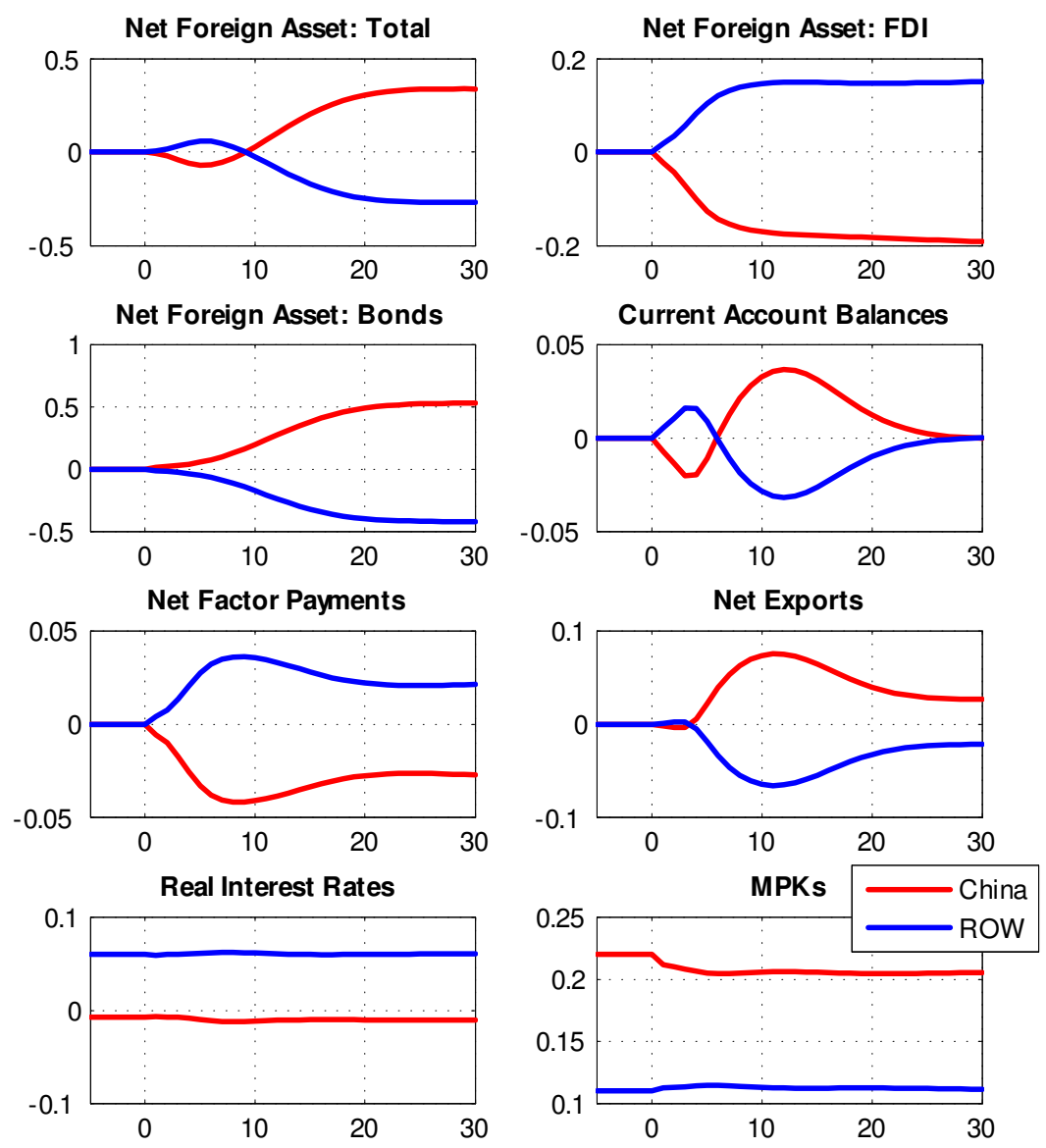

Figure 6. Transitional Dynamics after Financial Liberalization

Despite positive net capital outflows (financial plus fixed), China runs a trade surplus that increases over time (red line in the third panel in the right column), reaching $7.5 \%$ of GDP 10 years after liberalization. The trade surplus gradually declines to $3 \%$ in the steady state. However, the current account in China decreases briefly, then increases in the following years and eventually balances itself in the long run (red line in the second panel on the right column). Since FDI earns a much higher rate of return than bonds, China always receives negative net income payments. As a result, China runs a permanent trade surplus while the ROW runs a permanent trade deficit. Hence, our model suggests that the global imbalances in world trade are sustainable in the long run even if the current accounts are perfectly balanced. Obstfeld and Rogoff (2007) have argued that a permanent trade imbalance is unsustainable, thus predicting that a reversal of the U.S. current account deficit is inevitable and that the future U.S. trade surplus requires substantial depreciation of the dollar's real exchange rate. Our model predicts instead that the U.S. is able to sustain a trade deficit of about $2 \%$ of GDP permanently with China unless financial markets in China develop to the same degree as those in the U.S. 
The smoothly increasing trends in the transitional dynamics of the two-way capital flows and current accounts are due partially to consumption smoothing and partially to the gradual liberalization process assumed in the transaction costs. But even if we eliminate the transaction costs and allow rapid liberalization, we would still generate smooth rising trends in financial capital flows and current accounts (see Appendix D.2). The reason for this is that a large and dramatic change in financial capital flows would mean a large and dramatic change in consumption, so the households have incentives to smooth consumption by smoothing international borrowing.

In addition, the bottom two panels show that the interest and the MPK are not largely affected under two-way capital flows, despite the colossal volume of capital flows after liberalization. There are two major reasons. First, financial liberalization per se does not eliminate the international transaction costs in capital flows or reduce the domestic borrowing limits in either economy. On the top of this, two-way capital flows reinforce these gaps because FDI inflows and financial asset outflows have the opposite effects on the interest rate and the MPK, offsetting their impacts on these asset returns. These two factors together generate the sustained gaps in asset returns between the two countries. It is, however, possible to find parameter configurations such that the U.S. interest rate can be significantly reduced by financial capital inflows from China (provided that the international transaction cost of bonds is small and the autarky interest rate in the U.S. is far from $1 / \beta$ due to severe financial frictions on the household side). But such parameter configurations would then prevent our model from quantitatively matching the volume and dynamic paths of two-way capital flows observed in the data. This brings us to Figure 7.

Figure 7 compares the model-simulated dynamic paths of capital flows in the home country (blue lines) and their actual paths in China (red lines), where the vertical axes represent the percentage of GDP. The top-left panel shows net FDI inflows into China, the top-right panel shows net financial asset outflows from China, and the bottom panel shows net exports of China. The simulated series closely track the trends in the Chinese data, indicating that the model can explain the dynamics of China's capital flows very well. Although our calibrations do not target net exports, the simulated path captures the general trend in the data. Moreover, the simulated series predict that by 2020 China's accumulated FDI inflows and foreign reserves (financial asset outflows) will reach about $20 \%$ and $53 \%$ of GDP, respectively. This will take another 10 years to accomplish (our sample period ends at 2010). The model also predicts that China's net exports will level off and gradually reach about $3 \%$ of GDP after 2017. Given the recent trends in the Chinese trade data, this prediction seems credible. 

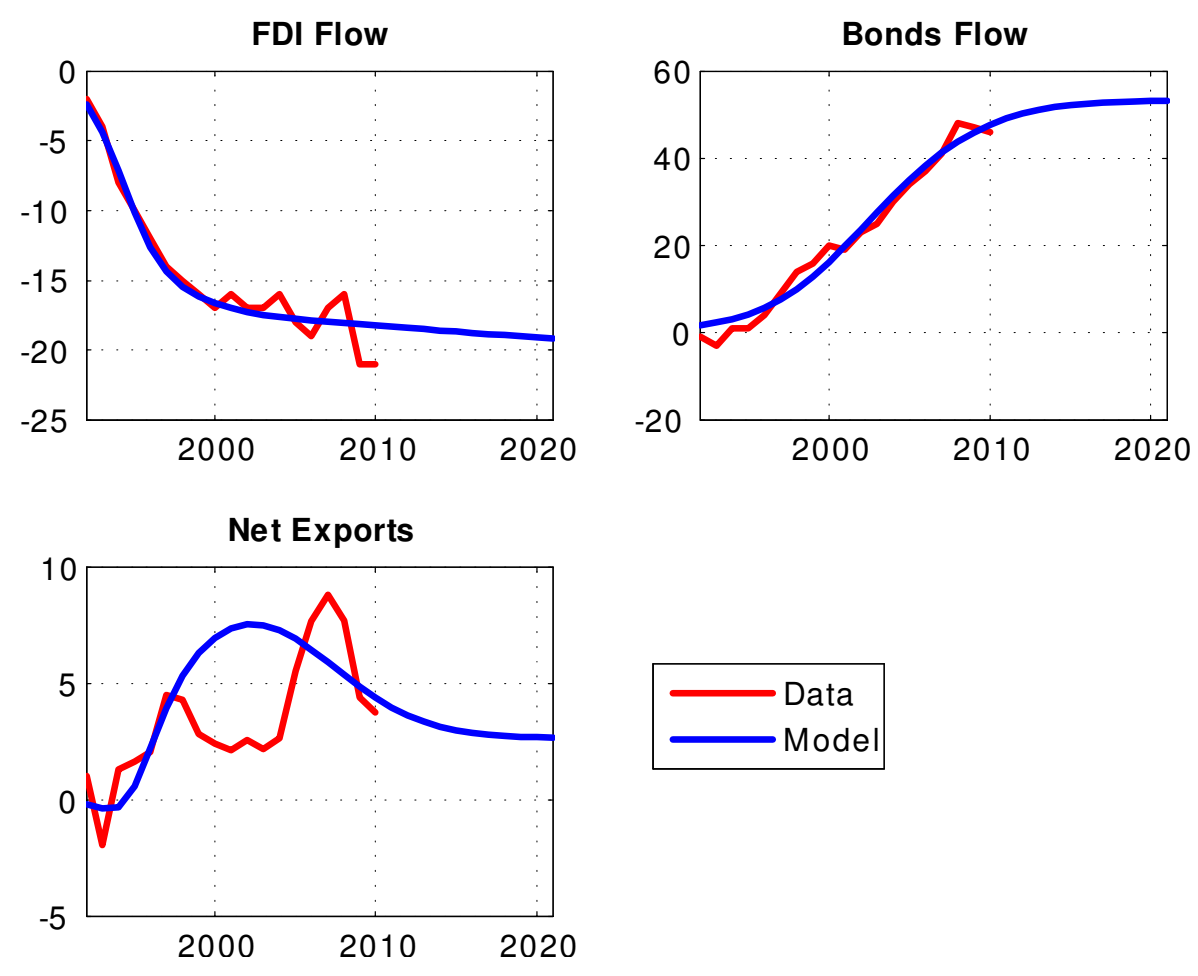

Figure 7. Net Foreign Asset Positions in China: Model v.s. Data

\section{Conclusions}

Capital flows both ways instead of one way between the North and the South: fixed capital flows from rich to poor countries whereas financial capital flows in the opposite direction. We augment the standard neoclassical growth model with two wedges (a saving wedge and an investment wedge) to quantitatively explain the magnitude of the two-way capital flows. We show that severe financial frictions in poor countries - the lack of an efficient banking-credit system in particular - can lead to insufficient investment on the firm side (the investment wedge) and excessive saving on the household side (the saving wedge). Consequently, fixed capital is scarcer while financial capital is relatively abundant in the South, creating a gap between the MPK and the real interest rate both within and across countries. This gap in assets returns drives the observed two-way capital flows between the North and the South.

Our contributions are therefore fourfold: (i) the ability to make a clear distinction between financial capital flows and fixed capital flows in a full-fledged two-country neoclassical growth model with double-heterogeneous agents; (ii) the ability to disentangle the interest rate from the MPK through Tobin's $q$ theory and show that the market rate of return to fixed capital can be over $20 \%$ a year in equilibrium despite low interest rates (as in China); ${ }^{39}$ (iii) the ability to explain

\footnotetext{
${ }^{39}$ In contrast to the existing approaches of studying FDI (e.g., MQR 2009), where FDI is modeled as households' portfolio choices through risky equity investment, we model FDI as firms' production decisions through international
} 
China's excessively high aggregate saving rate of $40 \%$ (despite low interest rates) and its massive trade imbalances with the ROW; and (iv) the ability to provide a tractable tool for evaluating the welfare consequences of the two fundamentally different forms of capital flows. ${ }^{40}$

Our main findings challenge the conventional wisdom in the global imbalance literature in several ways. For example, our model predicts that permanent global trade imbalances are sustainable (with the North running deficits and the South running surpluses). Also, our quantitative analysis shows that the impact of massive financial capital flows (from emerging markets to developed economies) on the world interest rate can be quantitatively small and negligible, in sharp contrast to the conjecture of Bernanke (2005). Another implication of our analysis is that the reduction of global imbalances (for better or worse) hinges neither on adjusting the exchange rates nor on capital account liberalization, but rather on improving emerging economies' banking system (i.e., reducing borrowing constraints facing both households and firms) so that household savings in the South can be channeled more effectively to its domestic production sector.

However, our model does not fully resolve the "allocation puzzle" of Gourinchas and Jeanne (2013) because we have not shown why countries with faster growth tend to attract less international capital. To fully resolve the "allocation puzzle", we need to introduce growth into our two-country model and show that the cross-country gaps in the financial interest rate and the MPK are increasing (rather than decreasing) functions of the growth rate (at least in the short run). This is beyond the scope of this paper and is thus left for future work (see Wen, 2009 and 2011, for critical progress in this direction).

factor allocation. Therefore, instead of creating the differential rates of return between bonds and FDI through equity premium, we achieve this through Tobin's $q$ theory - a standard approach in line with the neoclassical investment theory.

${ }^{40}$ Interested readers should refer to our working paper (Wang, Wen and Xu, 2013). 


\section{References}

[1] Aiyagari, S.R., 1994, "Uninsured Idiosyncratic Risk and Aggregate Saving," The Quarterly Journal of Economics, 109(3), pp. 659-84.

[2] Andolfatto, D., 2012, "Liquidity Shocks, Real Interest Rates, and Global Imbalances," Federal Reserve Bank of St. Louis Review, May/June 2012.

[3] Angeletos, G.M. and V. Panousi, 2011, "Financial integration, entrepreneurial risk and global imbalances," NBER Working Paper 16761.

[4] Bai C., C. Hsieh and Y. Qian, 2006, "The Return to Capital in China," Brookings Papers on Economic Activity, 37(2), pp. 61-102.

[5] Bernanke, B., 2005, "The Global Saving Glut and the U.S. Current Account Deficit", The Federal Reserve Board Speech.

[6] Buera, F. and Y. Shin, 2010, "Productivity growth and capital flows: The dynamics of reform," Working Paper, Washington University in St. Louis.

[7] Caballero, R., E., Farhi, and P-O., Gourinchas, 2008, "An equilibrium model of global imbalances and low interest rates," American Economic Review, 98(1), pp. 358-393.

[8] Carroll, C. and O. Jeanne, 2009, "A tractable model of precautionary reserves, net foreign assets, or sovereign wealth funds," Working Paper Series WP 09-10, Peterson Institute for International Economics.

[9] Chien, Y.L. and K. Naknoi, 2011, "The risk premium and long-run global imbalances," Purdue University Working Paper.

[10] Cochrane, J., 1991, "Production-Based Asset Pricing and the Link between Stock Returns and Economic Fluctuations," Journal of Finance, 46(1), pp. 209-37.

[11] Covas, F., and W., Den Haan, 2011, "The Cyclical Behavior of Debt and Equity Finance," American Economic Review, 101(2), pp. 877-899.

[12] Durdu, C., E., Mendoza and M., Terrones, 2009, "Precautionary demand for foreign assets in Sudden Stop economies: An assessment of the New Mercantilism," Journal of Development Economics 89(2), pp. 194-209.

[13] Gourinchas, P-O. and O. Jeanne, 2013, "Capital flows to developing countries: The allocation puzzle." Review of Economic Studies, pp. 1-32. 
[14] Hansen, L., and S., Richard, 1987, "The Role of Conditioning Information in Deducing Testable," Econometrica, 55(3), pp. 587-613.

[15] Hayashi, F., 1982, "Tobin's marginal q and average q: A neoclassical interpretation," Econometrica 50(1), pp. 213-224.

[16] Ju J. and S-J., Wei, 2010, "Domestic Institutions and the Bypass Effect of International Capital Flow," American Economic Journal: Economic Policy, 2(4), pp. 173-204.

[17] King, R.. and R., Levine, 1993. "Finance, entrepreneurship and growth: Theory and evidence," Journal of Monetary Economics, 32(3), pp. 513-542.

[18] King, R. and S., Rebelo, 1999. "Resuscitating real business cycles," Handbook of macroeconomics, 1, pp. 927-1007.

[19] Kiyotaki, N., and Moore, J., 1997. "Credit Cycles," Journal of Political Economy, 105(2), pp. 211-248.

[20] Lane, P.R., and G.M., Milesi-Ferretti, (2007). "The external wealth of nations mark II: Revised and extended estimates of foreign assets and liabilities, 1970-2004," Journal of International Economics 73, pp 223-250.

[21] Lucas, R., 1990. "Why Doesn't Capital Flow from Rich to Poor Countries?," American Economic Review, 80(2), pp. 92-96.

[22] Mian, A., and A., Sufi, 2011, "House Prices, Home Equity-Based Borrowing, and the US Household Leverage Crisis," American Economic Review, 101(5), pp. 2132-56.

[23] Mendoza, E., V., Quadrini and J-V., Rois-Rull, 2009, "Financial Integration, Financial Development, and Global Imbalances," Journal of Political Economy, 117(3), pp. 371-416.

[24] Obstfeld, M., and K., Rogoff, 2007, "The Unsustainable U.S. Current Account Position Revisited," NBER Chapters, in: G7 Current Account Imbalances: Sustainability and Adjustment, pp. 339-376.

[25] Ohanian L. and M. Wright, 2007, "Where Did Capital Flow? Fifty Years of International Rate of Return Differentials and Capital Flows," Working Paper.

[26] Poterba, J., 1998. "The rate of return to corporate capital and factor shares: new estimates using revised national income accounts and capital stock data," Carnegie-Rochester Conference Series on Public Policy, 48(1), pp. 211-246. 
[27] Sandri, D., 2010, "Growth and capital flows with risky entrepreneurship," IMF Working Paper $\mathrm{WP} / 10 / 36$.

[28] Song, Z., K. Storesletten, and F. Zilibotti, 2011, "Growing like China," American Economic Review, 101, pp. 202-241.

[29] Wang, P., and Y., Wen, 2012, "Hayashi meets Kiyotaki and Moore: A theory of capital adjustment costs," Review of Economic Dynamics 15(2), pp. 207-225.

[30] Wang, P., Y. Wen and Z., Xu, 2013, "Two-Way Capital Flows and Global Imbalances: A Neoclassiccal Analysis," Federal Reserve Bank of St. Louis Working Paper 2012-016A.

[31] Wang, P., L., Xu and Z., Xu, 2011, "Financial Development and Aggregate Saving Rates: A Hump-Shaped Relationship,” mimeo., Hong Kong University of Science and Technology.

[32] Wen, Yi, 2009, "Saving and growth under borrowing constraints: Explaining the high saving rate puzzle," Federal Reserve Bank of St. Louis Working Paper 2009-045C..

[33] Wen, Yi, 2011, "Explaining China's Trade Imbalance Puzzle," Federal Reserve Bank of St. Louis Working Paper 2011-018A. 


\section{Appendix}

\section{A Decision Rules and System of Equations}

\section{A.1 A Single Firm's Decision Rules}

We define MPK (net of depreciation rate $\delta$ ) as $M P K_{t}=R_{k t}-\delta$. The following proposition shows that $\left\{r_{t}, R_{k t}\right\}$ are both independent of firms' idiosyncratic shocks and are closely related to each other.

Proposition 3 Given $\left\{r_{t}, r_{t}^{f}\right\}$, the optimal FDI decision $\left(u_{j t}\right)$ is given by

$$
u_{j t}=\left\{\begin{array}{cc}
0 & \text { if } r_{t}^{f} \leq r_{t} \\
\left(\frac{r_{t}^{f}-r_{t}}{\gamma_{k}}\right)^{\frac{1}{\chi}} & \text { if } r_{t}^{f}>r_{t}
\end{array}\right.
$$

and the MPK is determined by

$$
M P K_{t} \equiv R_{k t}-\delta=r_{t}+\mathbf{1}_{r_{t}^{f}>r_{t}}\left[\frac{\chi}{1+\chi} \gamma_{k}^{-\frac{1}{\chi}}\left(r_{t}^{f}-r_{t}\right)^{\frac{1+\chi}{\chi}}\right]-\delta
$$

where $1_{r_{t}^{f}>r_{t}}$ is an index function that takes a value of 1 whenever $r_{t}^{f}>r_{t}$ and a value of 0 otherwise.

Proof. See Appendix B.1.

A firm's FDI decision depends completely on the spread of MPK between the two countries. It can be shown easily that the function $M P K$ is strictly increasing in $r_{t}$ and weakly increasing (non-decreasing) in $r_{t}^{f}$. Because of the constant returns to scale (CRS) production function and i.i.d. investment-efficiency shocks, both $R_{k t}$ and $r_{t}$ are independent of firms' idiosyncratic shocks. Based on this important property, we conjecture that the value of a firm is given by the following functional form suggested by Hayashi (1982):

$$
V_{t}\left(K_{j t}\right)=v_{t} K_{j t}
$$

where $v_{t}$ is the average (and marginal) value of a firm and depends only on the aggregate states. Hence, it is free of the firm index $j$. We define $q_{t}=\rho E_{t} \frac{\Lambda_{t+1}}{\Lambda_{t}} v_{t+1}$, which is the conventional measure of Tobin's q. With the conjectured value function, the firm's investment problem becomes

$$
v_{t} K_{j t}=\int_{\varepsilon_{j t}} \max _{I_{j t}}\left\{R_{k t} K_{j t}-I_{j t}+q_{t}\left[(1-\delta) K_{j t}+\varepsilon_{j t} I_{j t}\right]\right\} d \Phi
$$


subject to the constraints $(20),(22)$, and

$$
L_{j t} \leq q_{t} \xi K_{j t}
$$

Proposition 4 There exists a cutoff $\bar{\varepsilon}_{t}=\frac{1}{q_{t}}$, such that the firm's optimal investment decisions follow a trigger strategy:

$$
I_{j t}=\left\{\begin{array}{cc}
q_{t} \xi K_{j t}+R_{k t} K_{j t} & \text { if } \varepsilon_{j t}>\bar{\varepsilon}_{t} \\
0 & \text { otherwise }
\end{array} .\right.
$$

In addition, the marginal value of the firm is given by

$$
v_{t}=R_{k t}+(1-\delta) q_{t}+\left(q_{t} \xi+R_{k t}\right) \Omega\left(q_{t}\right)
$$

where $\Omega\left(q_{t}\right) \equiv \int_{\varepsilon_{j t}>1 / q_{t}}\left(q_{t} \varepsilon_{j t}-1\right) d \Phi$ with $\Omega^{\prime}\left(q_{t}\right)>0$, and Tobin's $q\left(q_{t}\right)$ evolves according to

$$
q_{t}=\rho E_{t} \frac{\Lambda_{t+1}}{\Lambda_{t}}\left[R_{k t+1}+(1-\delta) q_{t+1}+\left(q_{t+1} \xi+R_{k t+1}\right) \Omega\left(q_{t+1}\right)\right]
$$

Proof. See Appendix B.2.

Briefly speaking, $v_{t}$ is the value of one unit of existing capital and $q_{t}$ is the value of one unit of newly installed capital. The marginal benefit of new investment is thus $q_{t} \varepsilon_{j t}$. Since the real cost of investment is 1 , investment is profitable if and only if $q_{t} \varepsilon_{j t}>1$ or $\varepsilon_{j t}>\bar{\varepsilon}_{t} \equiv 1 / q_{t}$, which defines the cutoff. In such a case, the firm is willing to borrow as much as possible to invest, so its borrowing constraint binds. This explains the investment decision rule in equation (46).

By definition, $q_{t}$ equals the discounted future value of one unit of capital in the next period $\rho E_{t} \frac{\Lambda_{t+1}}{\Lambda_{t}} v_{t+1}$, which is equation (48) after substitution using equation (47). The average (marginal) value of the firm $\left(v_{t}\right)$ consists of three parts on the right-hand side of equation (47). First, one unit of capital can generate $R_{k t}$ units of operating profit in period $t$. Second, one unit of capital can carry $1-\delta$ remaining units to the next period with value $(1-\delta) q_{t}$ after depreciation. Finally, the capital can also be used as collateral. With probability $1-\Phi\left(\frac{1}{q_{t}}\right)$, the firm has a profitable investment opportunity and one unit of capital is able to obtain $q_{t} \xi$ units of loans, which can expand investment by $\left(q_{t} \xi+R_{k t}\right)$ units by equation (46). After repaying the loans at zero interest rate, the net value of the loan is $\left(q_{t} \varepsilon_{j t}-1\right)$; hence, the value of the collateral is $\left(q_{t} \xi+R_{k t}\right) \int_{\varepsilon_{j t}>1 / q_{t}}\left(q_{t} \varepsilon_{j t}-1\right) d \Phi$. This explains equation (48). 


\section{A.2 A Single Household's Decision Rules}

Proposition 5 The optimal demand for foreign bond holdings $\tilde{s}_{i t+1}$ is given by

$$
\tilde{s}_{i t+1}=\left\{\begin{array}{cc}
0 & \text { if } R_{b t} \geq R_{b t}^{f} \\
\left(\frac{R_{b t}^{f}-R_{b t}}{\gamma_{s}}\right)^{\frac{1}{\tau}} & \text { if } R_{b t}<R_{b t}^{f}
\end{array} .\right.
$$

Further, arbitrage among financial assets implies that the portfolio's price satisfies

$$
Q_{t}=\frac{Q_{t+1}+D_{t+1}}{R_{b t}}
$$

Namely, the risk-free rate is the proper discounting factor for the firms.

Proof. See Appendix B.3.

The demand for foreign bonds is an increasing function of the cross-country interest spread, $R_{b t}^{f}-$ $R_{b t}$, provided that the spread is positive. The parameter $\gamma_{s}$ determines the cost of holding foreign bonds; it thus represents the extent of capital controls or transaction costs in the international bonds market. Financial autarky for bond trading is obtained if $\gamma_{s}=\infty$. In the limit as $\gamma_{s} \rightarrow 0$,

the two interest rates, $R_{b t}^{f}$ and $R_{b t}$, must be equalized in general equilibrium, so the model reduces to the standard setting with a single international bond.

Note that even households with large preference shocks (or with a strong urge to consume) may still hold positive amount of foreign bonds $\tilde{s}_{i t+1}$ provided that $R_{b t}^{f}>R_{b t}$, because they can borrow from the domestic bond market, i.e., $s_{i t+1}<0$. More importantly, equation (49) implies that the country with a lower interest rate will have positive net outflows in financial capital. Thus, to show the direction of financial capital flows, we only need to compare the interest rates in the two countries.

Denoting by

$$
H_{i t}=\left(Q_{t}+D_{t}\right) a_{i t}+W_{t} n_{i t}+R_{b t-1} s_{i t}+R_{b t-1}^{f} \tilde{s}_{i t}-\gamma_{s}\left(\tilde{s}_{i t}\right)^{1+\tau} /(1+\tau)
$$

the gross wealth of household $i$ in period $t$, the following proposition shows that a household's consumption-saving decisions follow simple rules and that the distribution of gross wealth is degenerate across households (i.e., $H_{i t}=H_{t}$ for all $i$ ).

Proposition 6 Given the real wage $W_{t}$ and the real interest rate $R_{b t}$, the optimal consumption and saving of household $i$ are given, respectively, by

$$
c_{i t}=\min \left\{\frac{\theta_{i t}}{\bar{\theta}_{t}}, 1\right\}\left(H_{t}+B_{t}\right),
$$




$$
s_{i t+1}+\tilde{s}_{i t+1}+a_{i t+1} Q_{t}=\max \left\{\frac{\bar{\theta}_{t}-\theta_{i t}}{\bar{\theta}_{t}}, 0\right\}\left(H_{t}+B_{t}\right)-B_{t}
$$

where the target wealth $H_{t}$ and the cutoff $\bar{\theta}_{t}$ are identical across households and jointly determined by the following two equations:

$$
\bar{\theta}_{t}=\beta R_{b t}\left(H_{t}+B_{t}\right) E_{t}\left(\frac{\psi}{W_{t+1}}\right)
$$

and

$$
W_{t} \int \frac{\max \left(\theta, \bar{\theta}_{t}\right)}{H_{t}+B_{t}} d \Phi=\psi
$$

Proof. See Appendix B.4.

\section{A.3 Wedges and System of Aggregate Dynamic Equations}

As we have illustrated already with our toy model, financial frictions introduce two wedges into our model compared with standard representative-agent neoclassical growth models. The saving wedge is introduced by borrowing constraints on the household side, and the investment wedge is introduced by borrowing constraints on the firm side. These wedges lead to low returns to household savings (financial interest rate) and high returns to firm investment (MPK), thus creating the driving forces of international two-way capital flows. To derive these wedges explicitly, consider the effective interest rate facing an "aggregate" (average) household and the effective rate of return to capital facing an "aggregate" (average) firm.

The CRS production technology implies that the equilibrium factor prices are $W_{t}^{\ell}=\frac{(1-\alpha) Y_{t}^{\ell}}{n_{t}^{\ell}}$ and $r_{t}^{\ell}=\frac{\alpha Y_{t}^{\ell}}{\bar{K}_{t}^{\ell}}$, where the aggregate output $Y_{t}^{\ell}=\left(\bar{K}_{t}^{\ell}\right)^{\alpha}\left(n_{t}^{\ell}\right)^{1-\alpha}$ and the aggregate capital stock $\bar{K}_{t}^{\ell}=u^{\ell_{c}} K_{t}^{\ell_{c}}+\left(1-u_{t}^{\ell}\right) K_{t}^{\ell}$. After aggregating households' decisions in equations (52) and (53) as well as the budget constraint, ${ }^{41}$ and combining with equations (54) and (55), we obtain

$$
\begin{gathered}
\frac{\Psi\left(\bar{\theta}_{t}^{\ell}\right) \bar{\theta}_{t}^{\ell}}{C_{t}^{\ell}}=\beta R_{b t}^{\ell} \frac{\Psi\left(\bar{\theta}_{t+1}^{\ell}\right) \bar{\theta}_{t+1}^{\ell}}{C_{t+1}^{\ell}} G\left(\bar{\theta}_{t+1}^{\ell}\right), \\
\frac{\Psi\left(\bar{\theta}_{t}^{\ell}\right) \bar{\theta}_{t}^{\ell}}{C_{t}^{\ell}} W_{t}^{\ell} G\left(\bar{\theta}_{t}^{\ell}\right)=\psi^{\ell},
\end{gathered}
$$

where

$$
G\left(\bar{\theta}_{t}^{\ell}\right)=\int \max \left(\frac{\theta}{\bar{\theta}_{t}^{\ell}}, 1\right) d F(\theta)>1
$$

\footnotetext{
${ }^{41}$ The individual budget constraint is $c_{i t}+s_{i t+1}+\tilde{s}_{i t+1}+a_{i t+1} Q_{t}=H_{i t}$, where $H_{i t}$ is defined in equation (51).
} 
captures the liquidity premium of cash flows and $\Psi\left(\bar{\theta}_{t}^{\ell}\right)=\int \min \left(\frac{\theta}{\overline{\bar{\theta}}_{t}^{\ell}}, 1\right) d F(\theta)$ captures the marginal propensity to consume. Equation (56) corresponds to the intertemporal Euler equations for consumption and saving and equation (57) to aggregate labor supply. If $\frac{\Psi\left(\bar{\theta}_{t}^{\ell}\right) \bar{\theta}_{t}^{\ell}}{C_{t}^{\ell}}$ is treated as the aggregate marginal utility of consumption, then the savings wedge introduced by the financial friction on the household side is captured by the function $G(\bar{\theta})$. Because $G(\bar{\theta})>1$, the equation shows that the interest rate is lower than the rate of time preference $\left(\beta R_{b}<1\right)$, suggesting that financial friction induces higher saving (Aiyagari, 1994). The labor supply equation shows that financial friction induces a higher labor supply. The intuition is that the positive probability of a binding borrowing constraint induces the agent to work harder to provide enough liquidity to reduce that probability. This means that the effective rate of return to labor is the real wage compounded by the liquidity premium $G(\bar{\theta})$.

On the firm side, the Euler equation for capital investment is

$$
q_{t}^{\ell}=\frac{1}{R_{b t}^{\ell}}\left[R_{k t+1}^{\ell}+(1-\delta) q_{t+1}^{\ell}+\left(q_{t+1}^{\ell} \xi^{\ell}+R_{k t+1}^{\ell}\right) \Omega\left(q_{t+1}^{\ell}\right)\right] .
$$

Notice that if $\Omega\left(q_{t}^{\ell}\right)=0$ and $q_{t}=1$, the above equation is simply a modified neoclassical first-order condition with respect to capital investment. Therefore $\Omega\left(q_{t}^{h}\right)>0$ together with $q_{t}>1$ captures the investment wedge. It can be shown that Tobin's $q\left(q_{t}\right)$ measures the gap between the MPK and the financial interest rate.

The equilibrium dynamics of the model are characterized by a system of dynamic rational expectations equations in terms of aggregate variables. Besides the above wedge equations representing financial frictions, the rest of the aggregate equations pertaining to the aggregate resource constraint, aggregate production function, aggregate capital accumulation, aggregate consumption, and aggregate investment are given, respectively, by

$$
\begin{gathered}
C_{t}^{\ell}+S_{t+1}^{\ell}+\tilde{S}_{t+1}^{\ell}+I_{t}^{\ell}+r_{t}^{\ell} u_{t}^{\ell_{c}} K_{t}^{\ell c}+\frac{\gamma_{s}\left(\tilde{S}_{t-1}^{\ell}\right)^{1+\tau}}{1+\tau}+\gamma_{k} \frac{\left(u_{t}^{\ell}\right)^{1+\chi}}{1+\chi} K_{t}^{h}=Y_{t}^{\ell}+R_{b t-1}^{\ell} S_{t}^{\ell}+R_{b t-1}^{\ell_{c}} \tilde{S}_{t}^{\ell} \\
Y_{t}^{\ell}=\left[u^{\ell_{c}} K_{t}^{\ell \ell}+\left(1-u_{t}^{\ell}\right) K_{t}^{\ell}\right]^{\alpha}\left(n_{t}^{\ell}\right)^{1-\alpha} . \\
K_{t+1}^{\ell}=\frac{\Gamma\left(q_{t}^{\ell}\right)}{\pi\left(q_{t}^{\ell}\right)} I_{t}^{\ell}+(1-\delta) K_{t}^{\ell}, \\
C_{t}^{\ell}=\frac{\Psi\left(\bar{\theta}_{t}^{\ell}\right)}{1-\Psi\left(\bar{\theta}_{t}^{\ell}\right)}\left(q_{t}^{\ell} K_{t+1}^{\ell}+S_{t+1}^{\ell}+\tilde{S}_{t+1}^{\ell}+B_{t}^{\ell}\right),
\end{gathered}
$$




$$
I_{t}^{\ell}=\pi\left(q_{t}^{\ell}\right)\left(R_{k t}^{\ell}+q_{t}^{\ell} \xi^{\ell}\right) K_{t}^{\ell}
$$

where $\pi\left(q_{t}^{\ell}\right) \equiv 1-\Phi\left(1 / q_{t}^{\ell}\right)$ and $\Gamma\left(q_{t}^{\ell}\right) \equiv \int_{\varepsilon>1 / q_{t}^{\ell}} \varepsilon d \Phi(\varepsilon)$. The cutoffs $\left\{\bar{\theta}_{t}, 1 / q_{t}\right\}$ provide sufficient statistic for the distribution of households and firms' allocations. To facilitate analysis, we assume that the borrowing limit of the households is proportional to some aggregate variables, $B_{t}^{\ell}=b^{\ell} q_{t}^{\ell} K_{t}^{\ell}$, where the parameter $b^{\ell} \geq 0$ measures the tightness of borrowing constraints on the household side. A specific borrowing limit such as this permits balanced growth and facilitates steady-state calibrations. The total household income in equation (60) comes from several sources: total domestic output, returns from domestic bonds, and returns from foreign bonds. The aggregate consumption in equation (63) is proportional to total saving and borrowing limits $\left(B_{t}\right)$. The aggregate investment is obtained through aggregating equation (46). For the financial autarky regime, we also add

$$
S_{t+1}^{\ell}=\tilde{S}_{t+1}^{\ell}=u_{t}^{\ell}=0
$$

For the financial liberalization regime, we also add

$$
\begin{gathered}
S_{t+1}^{\ell}+\tilde{S}_{t+1}^{\ell_{c}}=0 \\
\tilde{S}_{t+1}^{\ell}=\mathbf{1}_{R_{b t}^{\ell_{c}}>R_{b t}^{\ell}}\left(\frac{R_{b t}^{\ell_{c}}-R_{b t}^{\ell}}{\gamma_{s}}\right)^{\frac{1}{\tau}} \\
u_{t}^{\ell}=\mathbf{1}_{r_{t}^{\ell}>r_{t}^{\ell}}\left(\frac{r_{t}^{\ell_{c}}-r_{t}^{\ell}}{\gamma_{k}}\right)^{\frac{1}{\chi}} .
\end{gathered}
$$

The system of equations (56)-(68) consists of 22 equations that determine the dynamic equilibrium path of 22 endogenous aggregate variables, $\left\{K_{t}^{\ell}, n_{t}^{\ell}, I_{t}^{\ell}, Y_{t}^{\ell}, q_{t}^{\ell}, C_{t}^{\ell}, \bar{\theta}_{t}^{\ell}, S_{t}^{\ell}, \tilde{S}_{t}^{\ell}, R_{b t}^{\ell}, u_{t}^{\ell}\right\}$, for $\ell=\{h, f\}$. The transitional equilibrium path from autarky to financial liberalization can all be computed in a straightforward manner by standard numerical methods in the representative-agent model literature.

\section{A.4 Aggregate Demand and Supply of Capital}

Deriving the aggregate demand and supply functions of capital can help us understand the subtle issues regarding the conditions of two-way capital flows in Section 5. We first derive the steady-state demand function for aggregate capital in the home country based on firms' investment behaviors. From the evolution equations of Tobin's $q$ (59) and capital stock (62) as well as the aggregate investment (64) in Appendix A.3, we obtain the following two equations that implicitly describe 
the gross rate of return to fixed capital $R_{k}$ (MPK) and Tobin's $q$ as functions of the real interest rate $R_{b}$ :

$$
\begin{gathered}
\delta=\left(R_{k}+q \xi\right) \Gamma(q) \\
R_{k}=q\left(R_{b}-1\right)+\delta \frac{1}{\Gamma(q) / \pi(q)} .
\end{gathered}
$$

where $\pi(q)=1-\Phi(1 / q)$, and $\Gamma(q)=\int_{\varepsilon>1 / q} \varepsilon d \Phi$. The term $\Gamma(q) / \pi(q)$ on the RHS of the last equation is the average investment efficiency for active firms; thus, it is increasing in the cutoff $1 / q$ or decreasing in $q$. This equation suggests that the Tobin's $q(q)$ measures the spread between the return to fixed capital and the return to financial capital (the interest rate). Indeed, if we assume that the efficiency shock $\varepsilon_{j}$ follows a binomial distribution with only two realizations, 0 and 1 , then the above equation reduces to $R_{k}-\delta=q\left(R_{b}-1\right)$. In this case, $q$ is exactly the wedge between the rate of return to fixed capital (MPK) and the real interest rate.

Combining equations (69) and (70), we can solve $R_{k}$ and $q$ as functions of the interest rate $R_{b}$ and the financial development parameter $\xi: R_{k} \equiv \mathbb{R}\left(R_{b}, \xi\right), q \equiv \mathbb{Q}\left(R_{b}, \xi\right)$. The following proposition shows that given the interest rate, the country with lower financial development $(\xi)$ on the firm side tends to have both a higher Tobin's $q$ and a higher MPK.

Proposition 7 The function of $M P K \mathbb{R}$ is strictly increasing in the interest rate $R_{b}$ and strictly decreasing in the financial development $\xi$, that is, $\frac{\partial \mathbb{R}\left(R_{b}, \xi\right)}{\partial R_{b}}>0$ and $\frac{\partial \mathbb{R}\left(R_{b}, \xi\right)}{\partial \xi}<0$. The function of Tobin's $q(\mathbb{Q})$ is strictly decreasing in both the interest rate $R_{b}$ and the financial development $\xi$, that is, $\frac{\partial \mathbb{Q}\left(R_{b}, \xi\right)}{\partial R_{b}}<0$ and $\frac{\partial \mathbb{Q}\left(R_{b}, \xi\right)}{\partial \xi}<0$.

Proof. Based on the fact that both $\Gamma(q)$ and $\frac{1}{\Gamma(q) / \pi(q)}$ are strictly increasing in $q$, the results can be obtained easily through the implicit function theorem.

Our model predicts that the MPK and financial interest rate are positively correlated but the correlation is not perfect - there is a wedge between the two and the magnitude of this wedge (Tobin's q) depends crucially on the degree of financial development. The wedge is smaller and the correlation is stronger for countries that are financially more developed. These predictions are consistent with the empirical findings of Ohanian and Wright (2007).

To obtain the aggregate capital demand function, we need to link the MPK to the capital-tooutput ratio. According to the previous discussions, the LHS of equation (70) is increasing in $r_{t}$ and thus decreasing in the capital-to-output ratio $\frac{\bar{K}}{Y}$. On the other hand, Proposition 7 implies that the RHS of equation (70) is increasing in the interest rate $R_{b}$. Therefore, equation (70) implicitly 
describes the aggregate capital demand (or the capital-to-output ratio) as a downward sloping function of the interest rate.

We now derive the aggregate capital supply from the household. From equation (57) in Appendix A.4, the cut-off $\bar{\theta}$ is implicitly determined by

$$
\beta R_{b} G(\bar{\theta})=1
$$

Since $G$ is a decreasing function of $\bar{\theta}$, equation (71) implies the cutoff is increasing in $R_{b}$. Since $G>1$, the financial frictions on the household side make the steady-state interest rate $R_{b}$ lower than $1 / \beta$. The presence of borrowing constraints limits households' ability to diversify the uninsurable risk $\theta$, thus inducing households to over-save to self-insure against risks. The oversaving behavior consequently reduces the interest rate in equilibrium.

Now, combining equations (60), (63) and (70), and with some algebra, we have

$$
\begin{aligned}
(1-\alpha)\left[(1-u)+\kappa u^{f}\right] \frac{Y}{\bar{K}} & =\left(\Upsilon-R_{b}+1\right) q+\Upsilon q b \\
& +\left(\Upsilon-R_{b}+1\right) \frac{S}{K}+\left[\Upsilon+1-\left(\frac{\tau}{1+\tau} R_{b}^{f}+\frac{1}{1+\tau} R_{b}\right)\right] \frac{\tilde{S}}{K},
\end{aligned}
$$

where $\Upsilon=\frac{\Psi}{1-\Psi}, \bar{K}=u^{f} K^{f}+(1-u) K$ is total world capital stock employed by the home country and $\kappa \equiv \frac{K^{f}}{K}$ is the relative ratio of fixed capital stocks in the two countries.

Equation (72) describes the aggregate supply of capital (capital-to-output ratio) for the home country as a positive function of the interest rate. Given $u^{f}$ and $\kappa$, the LHS of the equation is decreasing in $\frac{\bar{K}}{Y}$ since both $1-u$ and $\frac{Y}{K}$ are decreasing in $\frac{\bar{K}}{Y}$; whereas given $R_{b}^{f}$ (and ignoring the terms $S$ and $\tilde{S}$ for simplicity), the RHS of (72) is decreasing in $R_{b}$ since both $\Psi$ and $q$ are decreasing functions of $R_{b}{ }^{42}$

\section{A.5 Proof of Proposition 2}

The proof proceeds in two steps. First, we show that there exist parameter values of financial development such that the home country in autarky has higher MPK and a lower interest rate. Then we show that under these parameter values, the home country, in financial liberalization, holds a positive position in financial capital and a negative position in fixed capital.

\footnotetext{
${ }^{42}$ Here we implicitly assume the term $\frac{1}{1-\Psi}-R_{b}$ is strictly positive. Indeed, this assumption holds under fairly weak conditions. To see this, since $\frac{1}{1-\Psi}-R_{b}>0$ implies $1-\Psi<1 / R_{b}$, from equation (71), we only need to show $1-\Psi<\beta G$. According to the definitions of $\Psi$ and $G$, the last inequality is equivalent to $(1-\beta) F(\bar{\theta})<\int_{\theta<\bar{\theta}} \frac{\theta}{\theta} d F+\beta \int_{\theta>\bar{\theta}} \frac{\theta}{\theta} d F$. Therefore, we only need to show $F(\bar{\theta})<\frac{\beta}{1-\beta}\left(\int_{\theta<\bar{\theta}} \frac{\theta}{\theta} d F+\int_{\theta>\bar{\theta}} \frac{\theta}{\theta} d F\right)$. This inequality always holds if we have $\frac{E(\theta)}{\bar{\theta}} \geq \frac{1-\beta}{\beta}$, which is easily satisfied under the conditions that $\beta \rightarrow 1$ and $b$ is not too large (to ensure $\bar{\theta} \ll \theta_{\max }$ ).
} 
Lemma 1 Suppose the home country has tighter borrowing constraints on the firm side, that $i s, \xi^{h}<\xi^{f}$, then for any $b^{f}$, there exist $\underline{b}$ and $\bar{b}$ such that if $b^{h} \in(\underline{b}, \bar{b}),{ }^{43}$ in the financial autarky regime, the home country has higher MPK and a lower real interest rate.

Proof of Lemma 1. In the financial autarky regime, the equilibrium return of capital $r^{\ell}$ (MPK) (or the inverse $\frac{K}{Y}$ ratio) and the real interest rate $R_{b}^{\ell}$ are determined by (30) and (31). In the autarky equilibrium $r^{\ell}$ and $R_{b}^{\ell}$ are the functions of financial developments $\left\{\xi^{\ell}, b^{\ell}\right\}$, which we denote as $r_{A u t}\left(\xi^{\ell}, b^{\ell}\right)$ and $R_{A u t}^{*}\left(\xi^{\ell}, b^{\ell}\right)$ respectively. As Proposition 7 shows, we have $\frac{\partial r_{A u t}\left(\xi^{\ell}, b^{\ell}\right)}{\partial b^{\ell}}>$ $0, \frac{\partial r_{A u t}\left(\xi^{\ell}, b^{\ell}\right)}{\partial \xi^{\ell}}<0$ and $\frac{\partial R_{A u t}^{*}\left(\xi^{\ell}, b^{\ell}\right)}{\partial b^{\ell}}>0$. Therefore, there exists $\bar{b}$ satisfying

$$
R_{\text {Aut }}^{*}\left(\xi^{f}, b^{f}\right)=R_{A u t}^{*}\left(\xi^{h}, \bar{b}\right)
$$

such that for any $b^{h}<\bar{b}$, we must have $R_{A u t}^{*}\left(\xi^{f}, b^{f}\right)>R_{A u t}^{*}\left(\xi^{h}, b^{h}\right) .{ }^{44}$ There also exists $\underline{b}$ satisfying

$$
r_{A u t}\left(\xi^{f}, b^{f}\right)=r_{A u t}\left(\xi^{h}, \underline{b}\right)
$$

such that for any $b^{h}>\underline{b},{ }^{45}$ we must have $r_{A u t}\left(\xi^{h}, b^{h}\right)>r_{A u t}\left(\xi^{f}, b^{f}\right)$. Note that $\bar{b}>\underline{b}$ because of $\frac{\partial \mathbb{R}\left(R_{b}^{\ell}, \xi^{\ell}\right)}{\partial R_{b}}>0$ and $\frac{\partial \mathbb{R}\left(R_{b}^{\ell}, \xi^{\ell}\right)}{\partial \xi}<0$.

Lemma 2 Suppose the home country has tighter borrowing constraints on the household side, i.e. $b^{h}<b^{f}$, and idiosyncratic investment efficiency $\varepsilon$ follows the Pareto distribution, then for any $\xi^{f}$, there exists $\bar{\xi}$ such that if $\xi^{h}<\bar{\xi}<\xi^{f}$, in the financial autarky regime, the home country has higher MPK and a lower real interest rate.

Proof of Lemma 2. From (69), the Pareto distribution of $\varepsilon$ implies the MPK (or $Y / K$ ) in the autarky regime is a linear function of $q$. Furthermore, (31) implies $R_{A u t}^{*}$ depends only on $b$ and not on $\xi$. Thus, according to Proposition $6, b^{h}<b^{f}$ implies $R_{\text {Aut }}^{*}\left(b^{h}\right)<R_{\text {Aut }}^{*}\left(b^{f}\right)$. On the other hand, similar to the proof of Lemma 1 , there exists $\bar{\xi}\left(\xi^{f}, b^{f}, b^{h}\right)$ satisfying

$$
r_{\text {Aut }}\left(\xi^{f}, b^{f}\right)=r_{\text {Aut }}\left(\bar{\xi}, b^{h}\right)>r_{\text {Aut }}\left(\xi^{f}, b^{h}\right)
$$

such that for any $\xi^{h}<\bar{\xi}<\xi^{f}$, we must have $r_{A u t}\left(\xi^{h}, b^{h}\right)>r_{A u t}\left(\xi^{f}, b^{f}\right)$.

\footnotetext{
${ }^{43}$ Of course, $\bar{b}$ and $\underline{b}$ are the functions of $\xi^{h}, \xi^{b}$ and $b^{f}$. Without risk of confusion, here we do not express them explicitly as $\bar{b}\left(\xi^{h}, \xi^{f}, b^{f}\right)$ and $\underline{b}\left(\xi^{h}, \xi^{f}, b^{f}\right)$.

${ }^{44}$ If we assume the investment efficiency shock follows Pareto distribution, it can be shown that the $R_{A u t}^{*}$ does not depend on $\xi$, therefore $\bar{b}$ is simply $b^{f}$. That is, the higher level of financial development of foreign country on the household side induces a higher interest rate.

${ }^{45}$ Note that since $\xi^{h}<\xi^{f}, \frac{\partial r_{A u t}\left(\xi^{\ell}, b^{\ell}\right)}{\partial \xi^{\ell}}<0$ implies $\underline{b}<b^{f}$.
} 
We now turn to proving Proposition 2 with one of the following conditions: (i) $\xi^{h}<\xi^{f}$ and $b^{h} \in(\underline{b}, \bar{b})$, as stated in Lemma 1 ; or (ii) $b^{h}<b^{f}, \xi^{h}<\bar{\xi}<\xi^{f}$ and $\varepsilon$ follows the Pareto distribution, as stated in Lemma 2. The pattern of two-way capital flows requires us to show that in the liberalization regime interest rates satisfy $R_{b}^{f}>R_{b}^{h}$ and MPKs satisfy $r^{h}>r^{f}$. We proceed with the proof by ruling out all the complementarity relationships.

First, we show $R_{b}^{f}=R_{b}^{h}$ is impossible. In this case, there is no financial capital flow across countries. Since $\mathbb{R}\left(R_{b}, \xi\right)$ is decreasing in $\xi$ and $\xi^{h}<\xi^{f}$, we must have $R_{k}^{h}>R_{k}^{f}$ and $r^{h}>r^{f}$. ${ }^{46}$ The higher MPK in home country attracts FDI from foreign country, i.e. $u^{f}>0$. FDI inflow will shift the capital supply downward. ${ }^{47}$ Consequently, FDI inflow reduces the interest rate in the home country and raises the interest rate in the foreign country. This means that unlike the autarky equilibrium, we have $R_{b}^{f}>R_{\text {Aut }}^{*}\left(\xi^{f}, b^{f}\right)>R_{\text {Aut }}^{*}\left(\xi^{h}, b^{h}\right)>R_{b}^{h}$, which contradicts $R_{b}^{f}=R_{b}^{h}$.

Second, we show $r^{h}=r^{f}$ is impossible. In this case, there is no FDI flow across countries, and $R_{k}^{h}=r^{h}=R_{k}^{f}=r^{f}$. Under the parameter values satisfying Lemma 1 or 2 , we must have $R_{b}^{h}<R_{b}^{f}$ since $\mathbb{R}\left(R_{b}, \xi\right)$ is decreasing in $\xi$ and increasing in $R_{b} .{ }^{48}$ The higher interest rate in the foreign country attracts bond inflow, which shifts the capital supply curve in the foreign country downward. In contrast, the bond outflow moves the capital supply curve in the home country upward. ${ }^{49}$ As a result, compared to the autarky regime, MPK in the home country increases and MPK in the foreign country falls. Therefore we have $r^{h}>r_{A u t}\left(\xi^{h}, b^{h}\right)>r_{A u t}\left(\xi^{f}, b^{f}\right)>r^{f}$, which is a contradiction with $r^{h}=r^{f}$.

Third, we show $R_{b}^{f}<R_{b}^{h}$ and $r^{h}>r^{f}$ are impossible. In this case, the home country experiences both FDI and bonds inflows, both of which shift the capital supply curve downwardly and thus reduce the interest rate: $R_{b}^{h}<R_{A u t}^{*}\left(\xi^{h}, b^{h}\right)$. In contrast, the FDI and bonds outflows in the foreign country shift both capital demand and supply curves upwardly. ${ }^{50}$ As a result, the interest rate in foreign country increases, i.e., $R_{b}^{f}>R_{A u t}^{*}\left(\xi^{f}, b^{f}\right)$. Since with the parameter values satisfying Lemma 1 or 2 , we have $R_{\text {Aut }}^{*}\left(\xi^{h}, b^{h}\right)<R_{\text {Aut }}^{*}\left(\xi^{f}, b^{f}\right)$, and thus we must have $R_{b}^{h}<R_{b}^{f}$, which

\footnotetext{
${ }^{46}$ Thus, we have already ruled out two combinations: $R_{b}^{f}=R_{b}^{h}$ and $r^{h}<r^{f}$ or $R_{b}^{f}=R_{b}^{h}$ and $r^{h}=r^{f}$.

${ }^{47}$ More specifically, in this case, the capital supply curve in the home country (Eqn. 72) takes the form $(1-\alpha)\left(1+\kappa u^{f}\right) \frac{Y^{h}}{\bar{K}^{h}}=\left(\frac{1}{1-\Psi^{h}}-R_{b}^{h}\right) q^{h}+\frac{\Psi^{h}}{1-\Psi^{h}} q^{h} b^{h}$. Since $\kappa u^{f}>0$, compared with the autarky regime, the supply curve shifts downward.

${ }^{48}$ Thus we rule out the combination $r^{h}=r^{f}$ with $R_{b}^{h} \geq R_{b}^{f}$.

${ }^{49}$ More specifically, in this case, the capital supply curve in the home country (Eqn. 72) takes the form $(1-\alpha) \frac{Y^{h}}{\bar{K}^{h}}=$ $\left(\frac{1}{1-\Psi^{h}}-R_{b}^{h}\right) q^{h}+\frac{\Psi^{h}}{1-\Psi^{h}} q^{h} b^{h}+\left[\frac{1}{1-\Psi^{h}}-\left(\frac{\tau}{1+\tau} R_{b}^{f}+\frac{1}{1+\tau} R_{b}^{h}\right)\right] \frac{\tilde{S}^{h}}{K^{h}}$. Since the last term on the RHS is greater than zero, compared with the autarky regime, the supply curve shifts upward.

${ }^{50}$ In particular, the FDI outflow simultaneously shifts capital demand and supply upward. The bonds outflow only shifts the capital supply upward.
} 
contradicts $R_{b}^{f}<R_{b}^{h}$. With the same logic, we can show $R_{b}^{f}>R_{b}^{h}$ and $r^{h}<r^{f}$ are impossible as well.

Hence, the home country in the fully liberalization regime has higher MPK and a lower interest rate. Consequently, the home country will hold a positive position in fixed capital and a negative position in financial capital.

\section{B Proof of Propositions in Appendix A (not intended for publi- cation)}

\section{B.1 Proof of Proposition 3}

Since the optimal labor demand in the domestic market and that in the foreign markets are given, respectively, by $N_{j t}=\left(\frac{1-\alpha}{W_{t}}\right)^{1 / \alpha}\left(1-u_{j t}\right) K_{j t}$ and $X_{j t}=\left(\frac{1-\alpha}{W_{t}^{f}}\right)^{1 / \alpha} u_{j t} K_{j t}$, the CRS production technology implies that the MPKs for domestic and foreign business can be expressed as $r_{t}=\alpha\left(\frac{1-\alpha}{W_{t}}\right)^{\frac{1-\alpha}{\alpha}}$ and $r_{t}^{f}=\alpha\left(\frac{1-\alpha}{W_{t}^{f}}\right)^{\frac{1-\alpha}{\alpha}}$, respectively. After substitution, the profit-maximization problem of the firm can then be simplified to

$$
\Pi_{j t} \equiv R_{k t} K_{j t}=\max _{u_{j t}}\left[r_{t}\left(1-u_{j t}\right)+r_{t}^{f} u_{j t}-\gamma_{k} \frac{\left(u_{j t}\right)^{1+\chi}}{1+\chi}\right] K_{j t}
$$

The optimal FDI decision variable $u_{j t}$ can be solved as

$$
u_{j t}=\left\{\begin{array}{cl}
0 & \text { if } r_{t}^{f} \leq r_{t} \\
\left(\frac{r_{t}^{f}-r_{t}}{\gamma_{k}}\right)^{\frac{1}{\chi}} & \text { if } r_{t}^{f}>r_{t}
\end{array}\right.
$$

Substituting the optimal FDI decision rules into the profit function gives equation (42).

\section{B.2 Proof of Proposition 4}

For each period $\mathrm{t}$, after the realization of $\varepsilon_{j t}$, firm $j$ chooses optimal investment level to solve following problem

$$
\max _{I_{j t}} R_{k t} K_{j t}-I_{j t}+q_{t}\left[(1-\delta) K_{j t}+\varepsilon_{j t} I_{j t}\right]
$$

subject to (21), (22) and (45). The objective function can be simply rewritten as $\left[R_{k t}+q_{t}(1-\delta)\right] K_{j t}-$ $\left(1-q_{t} \varepsilon_{j t}\right) I_{j t}$. Define the cutoff $\bar{\varepsilon}_{t} \equiv 1 / q_{t}$. For $\varepsilon_{j t}>\bar{\varepsilon}_{t}$, firm $j$ will invest as much as it can, therefore (21) and (45) are binding - that is, $I_{j t}=q_{t} \xi K_{j t}+R_{k t} K_{j t}$. For the $\varepsilon_{j t} \leq \bar{\varepsilon}_{t}$, firm $j$ will 
choose the minimum investment, i.e., the zero level due to the irreversibility constraint. By inserting the optimal investment into (44), we can easily obtain the marginal value of the firm $v_{t}=R_{k t}+(1-\delta) q_{t}+\left(q_{t} \xi+R_{k t}\right) \Omega\left(q_{t}\right)$, where $\Omega\left(q_{t}\right) \equiv \int_{\varepsilon_{j t}>\bar{\varepsilon}_{t}}\left(q_{t} \varepsilon_{j t}-1\right) d \Phi$ with $\Omega^{\prime}\left(q_{t}\right)>0$.

Furthermore, from the definition $q_{t} \equiv \rho E_{t} \frac{\Lambda_{t+1}}{\Lambda_{t}} v_{t+1}$, the evolution of $q_{t}$ is thus

$$
q_{t}=\rho E_{t} \frac{\Lambda_{t+1}}{\Lambda_{t}}\left[R_{k t+1}+(1-\delta) q_{t+1}+\left(q_{t+1} \xi+R_{k t+1}\right) \Omega\left(q_{t+1}\right)\right]
$$

\section{B.3 Proof of Proposition 5}

Denote $\left\{\pi_{i t}, \mu_{i t}, \lambda_{i t}\right\}$ as the Lagrangian multipliers for constraints (9), (10), and (12), respectively. The first-order condition for labor is

$$
W_{t} \int \lambda_{i t} d F(\theta)=\psi
$$

Since labor is determined in the first subperiod of $t$ before observing $\theta_{i t}$, the household knows only the expected value of $\lambda_{i t}$ when making labor supply decisions. The first-order conditions for $\left\{c_{i t}, s_{i t+1}, s_{i t+1}, a_{i t+1}\right\}$ are given, respectively, by

$$
\begin{gathered}
\frac{\theta_{i t}}{c_{i t}}=\lambda_{i t}, \\
\lambda_{i t}-\pi_{i t}=\beta E_{t}\left(\lambda_{i t+1} R_{b t}\right), \\
\lambda_{i t}-\pi_{i t}-\mu_{i t}=\beta E_{t}\left[\lambda_{i t+1}\left(R_{b t}^{f}-\gamma_{s}\left(s_{i t+1}\right)^{\tau}\right)\right], \\
\lambda_{i t}-\pi_{i t}=\beta E_{t}\left(\lambda_{i t+1} \frac{D_{t+1}+Q_{t+1}}{Q_{t}^{h}}\right) .
\end{gathered}
$$

Note that by arbitrage, bonds and equities must yield the same expected rate of return. Hence, equations (82) and (84) imply $R_{b t}=\frac{D_{t+1}+Q_{t+1}}{Q_{t}^{h}}$ in the absence of aggregate uncertainty. ${ }^{51}$ Rewriting this relationship, we obtain equation (50). From equations (82) and (83), we can obtain equation (49).

\footnotetext{
${ }^{51}$ With aggregate uncertainty, the result hold $d$ s to a first-order approximation.
} 


\section{B.4 Proof of Proposition 6}

For simplicity, here we drop the superscript $h$. We first prove that the total wealth $H_{i t}=\left(Q_{t}+D_{t}\right) a_{i t}+$ $W_{t} n_{i t}+s_{i t}+\tilde{s}_{i t}-\gamma_{s}\left(\tilde{s}_{i t}\right)^{\tau} /(1+\tau)$ is degenerate. In the second subperiod, the households' consumption, saving, and stock holdings can be written as functions of its own wealth $H_{i t}$, liquidity shock $\theta_{i t}$, and aggregate variables. We hence have

$$
\lambda_{i t}=\frac{\theta_{i t}}{c_{i t}}=\frac{\theta_{i t}}{c_{t}\left(H_{i t}, \theta_{i t}\right)}
$$

Equation (82) can then be written as

$$
\begin{aligned}
\frac{\theta_{i t}}{c_{t}\left(H_{i t}, \theta_{i t}\right)} & =\beta R_{b t} E_{i}\left[\lambda_{i t+1}\right]+\pi_{i t} \\
& =\beta R_{b t} \frac{\psi}{W_{t+1}}+\pi_{i t},
\end{aligned}
$$

where the second line makes use of equation (80). Define $\bar{\theta}_{i t}$, such that

$$
\frac{\bar{\theta}_{i t}}{H_{i t}+B_{t}}=\beta R_{b t} \frac{\psi}{W_{t+1}}
$$

Since $c_{i t} \leq H_{i t}+B_{t}$, we must have $\frac{\theta_{i t}}{c_{t}\left(H_{i t}, \theta_{i t}\right)} \geq \frac{\bar{\theta}_{i t}}{H_{i t}+B_{t}}$ for $\theta_{i t} \geq \bar{\theta}_{i t}$. By (86) and (87), we must have $\pi_{i t}>0$. Or the borrowing constraint (9) binds, and the household's consumption is $c_{i t}=H_{i t}+B_{t}$. On the other hand, $\pi_{i t}=0$, we must have

$$
\frac{\theta_{i t}}{c_{t}\left(H_{i t}, \theta_{i t}\right)}=\frac{\bar{\theta}_{i t}}{H_{i t}+B_{t}}
$$

or $c_{i t}=\left(H_{i t}+B_{t}\right) \frac{\theta_{i t}}{\bar{\theta}_{i t}}$. Since $c_{i t}<H_{i t}+B_{t}$, we must have $\theta_{i t}<\bar{\theta}_{i t}$. Finally, using the consumption rule derived above, we rewrite equation (80) as

$$
\frac{W_{t}}{\psi}\left[\int_{\theta<\bar{\theta}_{i t}} \frac{\bar{\theta}_{i t}}{H_{i t}+B_{t}} f(\theta) d \theta+\int_{\theta>\bar{\theta}_{i t}} \frac{\theta}{H_{i t}+B_{t}} f(\theta) d \theta\right]=1 .
$$

Equation (87) and (89) jointly determine $\bar{\theta}_{i t}$ and $H_{i t}$. It is evident that $H_{i t}$ and $\bar{\theta}_{i t}$ depend only on aggregate variables in the economy; hence we have $H_{i t}=H_{t}$ and $\bar{\theta}_{i t}=\bar{\theta}_{t}$. By dropping the subscript $i$ from equation (87), we obtain equation (54). If we write equation (89) more compactly and drop the subscript $i$, we obtain equation (55). The rest of equations (52) and (53) are straightforward to obtain. 


\section{Data (not intended for publication)}

\section{C.1 Data Description}

1. U.S. net position of direct investment abroad relative to China (blue line in Figure 1A). The Bureau of Economic Analysis produces comprehensive statistics on U.S. direct investment abroad through the mandatory surveys. U.S. direct investment abroad is defined as ownership by a U.S. investor of at least 10 percent of a foreign business. Direct investment position statistics are in terms of total stock (or cumulative); they measure the total outstanding level of U.S. direct investment abroad at year end. The series used in our paper is the item "Position of direct investment abroad on a historical-cost basis" from the BEA website. ${ }^{52}$

2. U.S. net positions in debt instruments relative to China (red line in Figure 1A). The U.S. collects data on cross-border portfolio investments through the Treasury International Capital reporting system. Cross-border portfolio investments include foreign holdings of U.S. long-term and short-term securities, and U.S. holdings of foreign long-term and short term securities. In our paper, we define the U.S. net debt position relative to China as the U.S. holdings of China's long-term and short-term debts net of China's holdings of U.S. long-term and short-term debts. Therefore, the negative value indicates net inflows of financial capital toward the U.S.

3. China's net financial capital investment. Dividing this series by China's GDP gives the red line in Figure 1B. Both series are updated from Lane and Milesi-Ferretti (2007).

4. China's net direct investment abroad. Dividing this series by China's GDP gives the blue line in Figure 1B. Both series are updated from Lane and Milesi-Ferretti (2007).

5. Rate of return to fixed capital (left panel in Figure 2). Here we briefly illustrate the method and data used in our calculations. Bai et al. (2006) use the following formula to calculate the real rate of return to capital $r(t)$ :

$$
r(t)=\frac{\alpha(t)}{P_{K}(t) K(t) /\left[P_{Y}(t) Y(t)\right]}+\left[\hat{P}_{K}(t)-\hat{P}_{Y}(t)\right]-\delta(t)
$$

where $\alpha(t)$ is the share of payments on capital; $P_{K}(t) K(t)$ and $P_{Y}(t) Y(t)$ are capital stock and GDP in current prices, respectively; $\hat{P}_{K}(t)$ and $\hat{P}_{Y}(t)$ are the growth rate of investment price deflator and GDP deflator, respectively; $\delta(t)$ is the depreciation rate. For China's capital return $r(t)$, we extend Bai's series to more recent years. For the U.S., we use the

\footnotetext{
${ }^{52}$ Comparing to the U.S. direct investment to China, the amount of foreign investment from China to U.S. is negligible, we use the former series to represent U.S. net position of direct investment abroad relative to China.
} 
same method. In particular, we compute the capital return for the nonfinancial corporate business in private sector. We also exclude the residential sectors; so $\alpha(t)$ is the capital share in U.S. nonfinancial corporate business defined as $1-\frac{\text { Compensation of employees }}{\text { Value added }}$ Both series are from "Table 1.14. Gross Value Added of Domestic Corporate Business in Current Dollars and Gross Value Added of Nonfinancial Domestic Corporate Business in Current and Chained Dollars" (BEA). $P_{K}(t) K(t)$ is the nonresidential capital stock (equipment and software plus structures) in current costs in nonfinancial corporate business, expressed in billions of dollars. Data are from "Table 4.1. Current-Cost Net Stock of Private Nonresidential Fixed Assets by Industry Group and Legal Form of Organization". $\delta(t)$ is the depreciation rate in U.S. private nonfinancial corporate business, defined as $\frac{\text { consumption of capital }}{\text { Capital Stock }}$. The data source is the same as $\alpha(t) . \hat{P}_{Y}(t)$ is the growth rate of GDP deflator, $\hat{P}_{K}(t)$ is the growth rate of Gordon price index for investment goods. The Gordon price index measures prices of a bunch of investment goods by quality adjustment. For the alternative calculation of the return of capital, we follow the simple definition in Poterba (1998) as (Profits before tax with IVA plus CCAdj + Net interest payments)/Capital stock, the data source is the same as $\alpha(t)$. Note that our calculated series is slightly higher than Poterba's results (only up to the data before 1996); this is probably because we do not include inventory and land in our capital stock definition.

6. Real interest rate (right panel in Figure 2). The annual lending rate in real terms. China's interest rate is risk-adjusted. Both series are downloaded from World Development Indicators (WDI).

7. Private credit-to-GDP ratio (Figure 3). The data are downloaded from the WDI, defined as the ratio of domestic credit to private sector to the GDP. It is a traditional indicator capturing one of the most important functions of financial intermediaries - credit allocation.

8. Components of the U.S. direct investment abroad and Chinese inward FDI. According to the BEA definition, foreign direct investment flows consists of four components:

(1) Equity investment, which is the difference between equity increases and equity decreases. Equity increases arise from

(a) parents' establishments of new affiliates,

(b) payments by parents to unaffiliated parties for the purchase of capital stock or other equity interests when they acquire an existing business,

(c) payments made to acquire additional ownership interests in affiliates, 
(d) capital contributions to affiliates. Equity decreases are the funds that parent firms receive when they reduce their equity interest in their affiliates.

(2) Intercompany debt investment, which results from changes in net outstanding loans between parents (or for inward investment, other foreign parent group members) and their affiliates, including loans by parents to affiliates and loans by affiliates to parents.

(3) Reinvested earnings (without current-cost adjustment), which are the parents' share of the current-period operating earnings of their affiliates, less distributions of earnings by affiliates to their parents.

(4) Various valuation adjustments to the historical-cost position are made to account for the differences between changes in the historical-cost positions, which are measured at book value, and direct investment financial flows, which are measured at transaction value. (Unlike the positions on current-cost and market-value bases, the historical-cost position is not usually adjusted to account for changes in the replacement cost of the tangible asset of affiliates or in the market value of parent companies equity in affiliates.

If we look only at the first 3 components, only items (b) and (c) in Equity investment correspond to the FDI in Mendoza et al. (2009). Items (a) and (d) in Equity investment, as well as Intercompany debt investment + Reinvested earnings, in our view, correspond to the definition of FDI in our model. In particular, the change of FDI (or U.S. FDI outflow) in our model can be expressed as

$$
\Delta F D I_{t}=u_{t}^{f} K_{t}^{f}-u_{t-1}^{f} K_{t-1}^{f},
$$

where the total earnings from FDI is $r_{t}^{h} u_{t}^{f} K_{t}^{f}$, which consists of reinvested earnings $\left(R E_{t}\right)$ and earnings distributed to parents $\left(E D_{t}\right)$. Therefore, $\Delta F D I_{t}$ can be further expressed as

$$
\Delta F D I_{t}=R E_{t}+\left[E D_{t}-r_{t}^{h} u_{t}^{f} K_{t}^{f}+\left(u_{t}^{f} K_{t}^{f}-u_{t-1}^{f} K_{t-1}^{f}\right)\right]
$$

The first term is reinvested earnings; the second term can be treated as $(\mathbf{a})+(\mathbf{d})+(\mathbf{2})+(\mathbf{3})$. Therefore, $\frac{(\mathrm{a})+(\mathrm{d})+(2)+(3)}{(1)+(2)+(3)}$ measures the fraction of FDI captured by our model. However, the BEA has only the series of equity investment, so we can calculate only the ratio $\frac{(2)+(3)}{(1)+(2)+(3)}$, which tends to understate the role of the form of FDI defined in our model. Collecting the relevant data and calculating the ratio $\frac{(2)+(3)}{(1)+(2)+(3)}$ for U.S-China FDI flows gives $0.76 .{ }^{53}$ As a

\footnotetext{
${ }^{53}$ The series used are from U.S. Direct Investment Abroad, i.e. FDI outflow from U.S. to China. Since FDI outflow
} 
robustness check, we also calculate the ratio $\frac{(2)+(3)}{(1)+(2)+(3)}$ for the total FDI outflow from U.S. to all countries and the value is about $0.62 .{ }^{54}$

According to the ownership of foreign-invested projects in China, the FDI inflows can be divided into four main categories: equity joint ventures (EJVs), cooperative operation enterprises or contractual joint ventures (CJVs), wholly foreign-owned enterprises (WFOs), and others. ${ }^{55}$ EJVs and CJVs both involve joint investment by Chinese and foreign partners, the main difference between these two types of FDI is the arrangement for sharing profit and losses. WFOs are the enterprises whose ownerships fully belong to foreigners. According to the above definitions, WFOs largely represent new businesses established and owned by foreign firms. The following figure reports the shares of WFOs and EJVs+CJVs in total FDI inflows to China. As can be seen, after China's accession to WTO in 2001, WFOs exceed EJVs+CJVs and become the dominant form of FDI inflows. Therefore, we can safely infer that new businesses set up by foreign firms play a dominant role in FDI inflows.

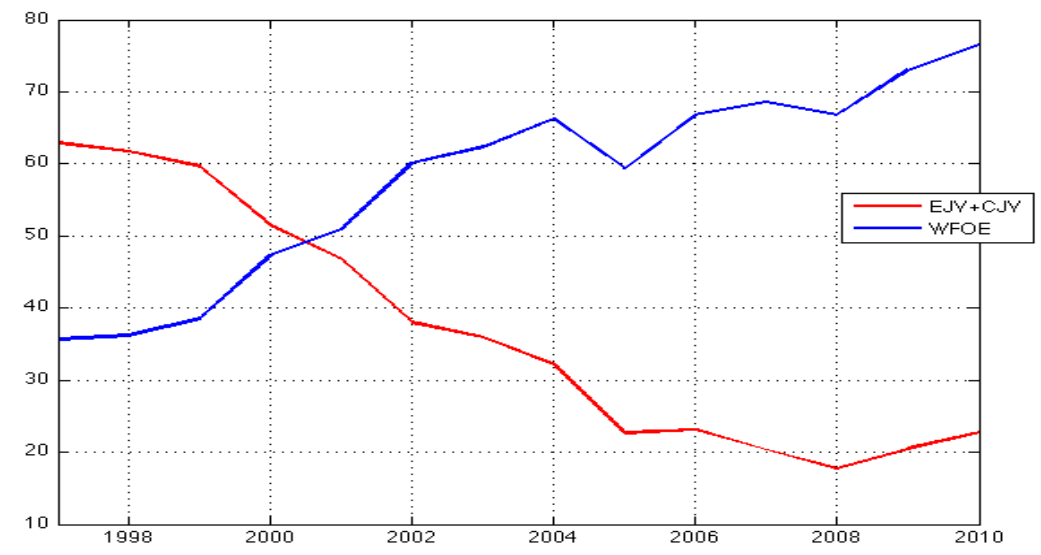

Figure A1. Percentage Shares of FDI Inflows by Type (data source: CEIC).

from China to U.S. is negligible and has very limited observations, we use the former series to represent net FDI flows between two countries. Next, we calculate the sum of each item. For instance, we sum (3), the reinvested earnings, from 1982 to 2010 to get the stock of FDI. We can then obtain the ratio through the formula $\frac{(2)+(3)}{(1)+(2)+(3)}$.

${ }^{54}$ In particular, the sum of intercompany debt (item (2)) from 1982 to 2010 is about $\$ 148,128$ million, the reinvested earnings (item (3)) is about $\$ 1,979,725$ million, and the equity investment (item (1)) is $\$ 1,264,370$ million. If we look at the net FDI outflow from U.S. to all countries, item (2) is $-\$ 323,179$ million, item (3) is $\$ 1,753,657$ million, and item (1) is $-1,205,846$ million. Therefore, in terms of absolute level, (2)+(3) still dominate (1).

${ }^{55}$ Catagory "Others" contains foreign sharing-holding enterprises (SH) and joint exploration (JE). 


\section{C.2 Alternative Measures of Financial Development}

1. The credit data we used in our paper is domestic credit (loan) to the private sector, obtained from World Development Indicators (WDI) database, which is widely used in the literature related to financial development (e.g., King and Levine, 1993). There is, however, an alternative data source, called debt borrowed by private non-financial sector from the BIS database. In the case of China, these two series were broadly similar up to the financial crisis, but diverged significantly since the financial crisis (see Figure A2 below, where the line with circles pertains to your BIS data and the dashed line pertains to our WDI series). It shows that the two series track each other closely prior to 2009, but after that the BIS series experienced sharp increases compared with the WDI series. This sharp discrepancy between WDI and BIS after 2009 is attributable to the fact that BIS includes (i) the entrusted and trust loans extended by non-bank financial institutions in China and (ii) corporate bonds issued in domestic bond market. These two components in China have seen rapid increases after 2009 due to policy interventions and the bulk of the increases were not related to private credit expansion to financing private fixed investment (which is what our paper is about), but to government (public) credit expansion to financing public infrastructure under policy interventions. According to the CEIC (a widely used database for Chinese macroeconomic data), during 2010Q1 to 2013Q4 the total trust funds rose to 12\% of China's GDP. Out of that, 28\% went to the infrastructure sector, $12 \%$ to the housing sector, $20 \%$ to the financial sector, and only the remaining $22 \%$ to the nonfinancial sector. Thus, only a minor part $(22 \%)$ of trust funds can be defined as domestic credit to private capital formation, which our paper models. In the mean time, for the corporate bonds issued in the domestic market, it is well believed that the major part of it in China is endorsed by the local governments for infrastructure investment. In the CEIC database, during 2010 to 2013 the total scale of corporate bonds was about $11 \%$ of GDP, around $87 \%$ of which were the corporate bonds issued by SOEs (under the request of both local and central governments to participate in the 4-trillon stimulus package lunched to combat the 2007 financial crisis). Therefore, we can conclude that the sharp increase in the debt-to-GDP ratio shown in the BIS series is mainly caused by public investment under government intervention policies instead of the improvement in the financial system for credit lending. This viewpoint is reinforced by the work of Wen and Wu (2014). They show that the leverage ratio in the pre-crisis period was similar between SOEs $(58.5 \%)$ and POEs (59.1\%), but the ratio during the stimulus period of 2008Q4-2010Q4 became quite different for these two groups of firms. On the one hand, the average leverage ratio of SOEs increased steadily, from $57.5 \%$ in 2008Q1 to $61.4 \%$ in 2009Q4. On the other hand, during the same period the average leverage ratio of POEs dropped continuously from the pre-crisis level 
of $59 \%$ down to $57 \%$. Therefore, the BIS series in our judgement is not a good indicator for China's financial development for the period after 2009 due to the financial crisis and policy interventions. Indeed, if we exclude the trust funds (except those to the nonfinancial sector) as well as the corporate bonds issued by SOEs from the BIS debt series, the adjusted series (the solid line in Figure A2) is much closer to the WDI series (the dashed line). In addition, even the adjusted BIS as well as WDI series in China tend to overstate the volume of private credit because they involve bank lending to SOEs and such credit flow is large and not subject entirely to market behavior. Indeed, according to recent data, the total liability of SOEs in the end of 2013 is around 60 trillion RMB (See the website of China's Ministry of Finance at http://qys.mof.gov.cn/zhengwuxinxi/qiyeyunxingdongtai/201312/t20131219_1026783.html), which is around $104 \%$ of China's GDP. Therefore, even the adjusted BIS and the WDI in Figure A2 tend to over-estimate the true level and trend of financial development in China.

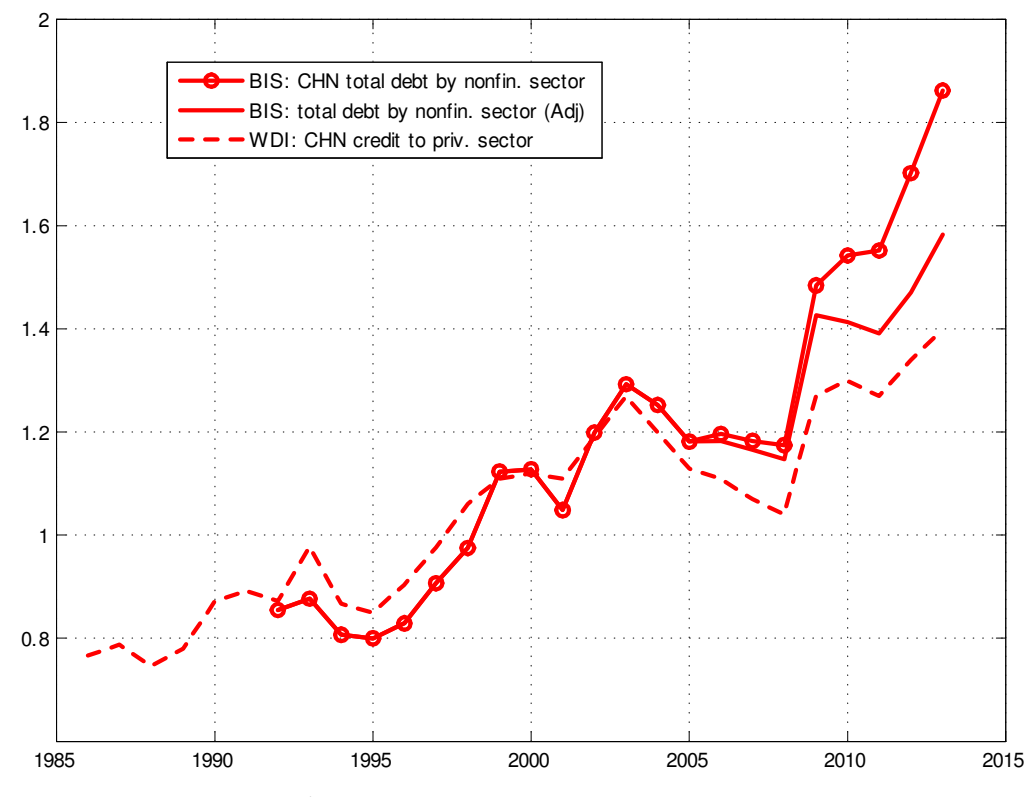

Figure A2. Credit-to-GDP ratios in China

2. The BIS data in the U.S., however, does not suffer too much from such SOE related problems, compared with China. Hence, we can compare the American BIS and WDI with the adjusted BIS and WDI of China to see if the disparity of financial development (measured by the private credit-to-GDP ratio) between the two countries remains large and persistent over time. Figure A3 below shows that the described pattern of development gap in our paper remains valid, where the blue solid line represents BIS of the US, blue dashed line the WDI of the US; the red solid line represents the adjusted BIS in China, and the red dashed line the WDI of China (the blue line with stars will be explained below). Clearly, despite the upward trend in these different financial-development indices in both countries, the financial 
development gap between the two countries remain large and persistent overtime. What is interesting to note is that in the US the WDI index lies substantially above the BIS index after 1995, unlike those in China. In order to double check this interesting behavior, we also provide in Figure A3 (blue solid line with stars) the US total liability of households and nonprofit organizations plus the total liability of nonfinancial corporate business (from Flow of Funds). This third series is quantitatively very similar to the US WDI series after 1995 (such Flow of Funds data is not available for China). Therefore, we feel comfortable to using the WDI series from both countries as the indicator of financial development in our paper.

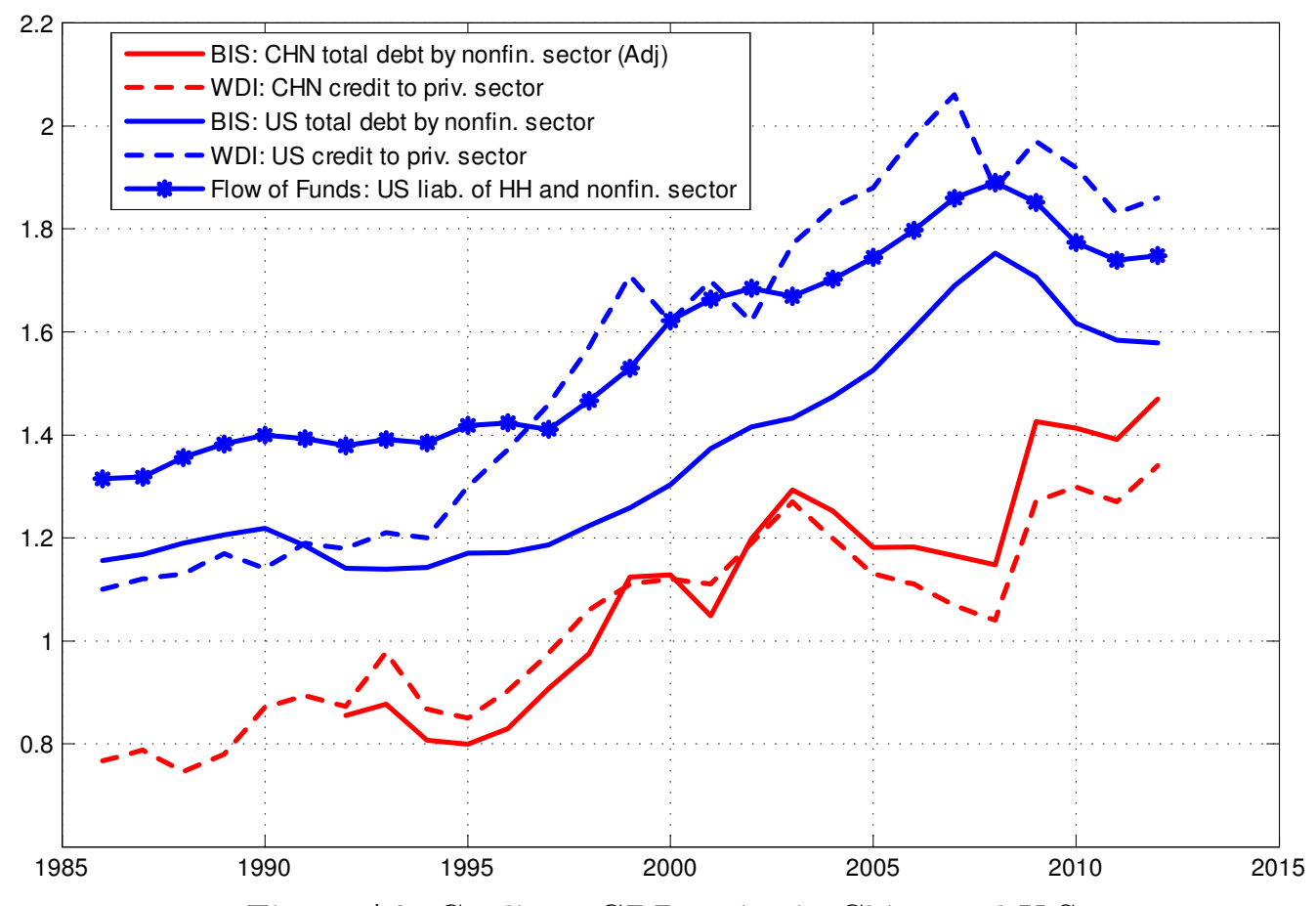

Figure A3. Credit-to-GDP ratios in China and U.S.

3. As a further robustness check, we also collect two additional indices for financial development from various sources. One is the financial reform index (only available for the periods before 2005) from a widely used database called "A New Database of Financial Reforms". ${ }^{56}$ This index considers seven aspects of financial system such as directed credit/reserve requirements, aggregate credit ceilings, credit controls, interest rate controls, entry barriers/pro-competition measures, banking supervision and privatization. Figure A4 compares this index for China and that for the US. As can be seen, China's index is significantly lower than that of the US, and the gap is quite persistent overtime.

\footnotetext{
${ }^{56}$ See Abiad, Abdul, Enrica Detragiache, and Thierry Tressel, (2010) "A New Database of Financial Reforms," IMF Staff Papers.
} 


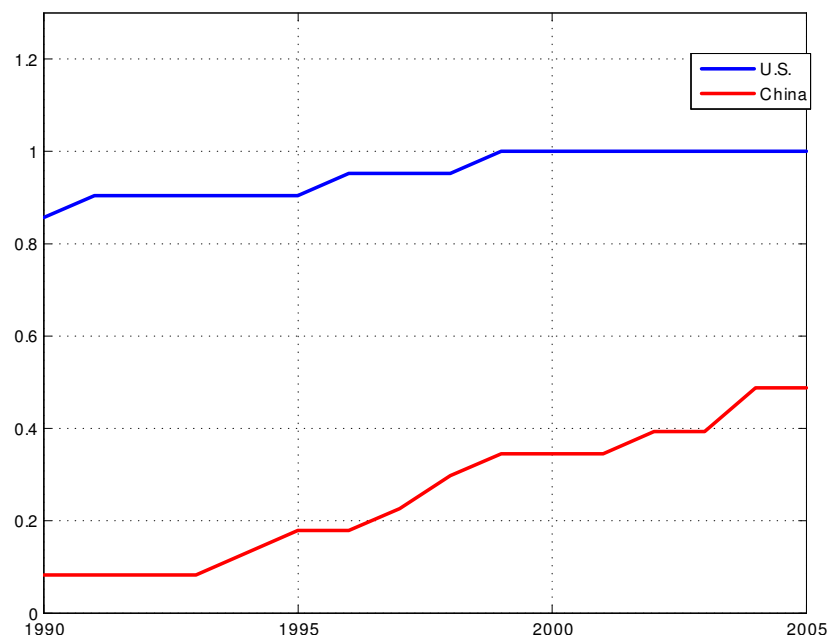

Figure A4. Financial reform index, 1990-2005. Data source: World Bank.

The second index of financial development is the financial development index (only available for the period 2008-2012) from the World Financial Development Report issued by the world economic forum. Figure A5 reports the indices for China and the US. Again, it shows that China has a much lower level of the financial development than that in the US, and that the gap between the two countries is highly persistent.

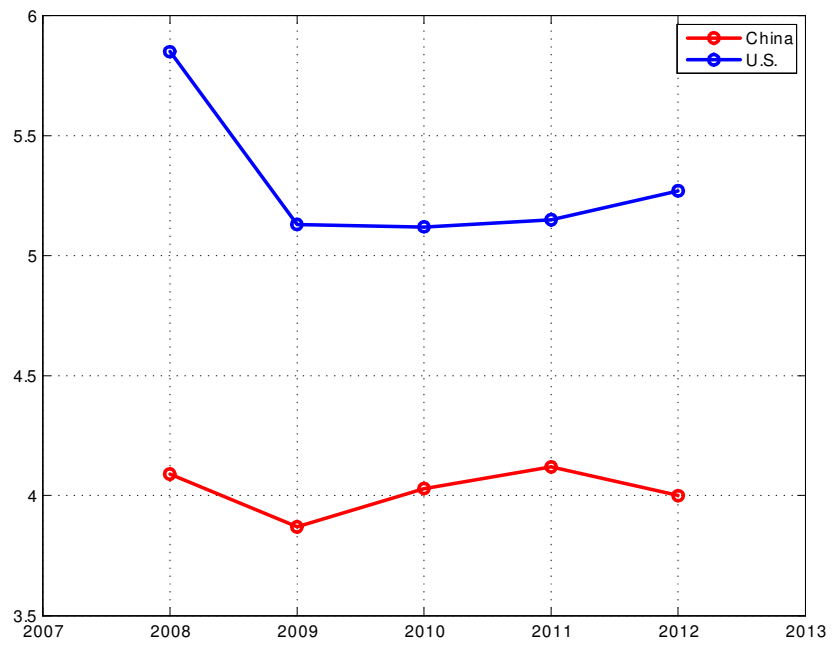

Figure A5. Financial development index: 2008-2012. Data source: World Economic Forum.

\section{Robustness Analysis (not intended for publication)}

\section{D.1 Alternative Parameter Settings}

We now conduct sensitivity analysis for the crucial parameters in borrowing constraints. In the previous calibration, we set $b^{f}=0.25$ according to Mian and Sufi (2011). That paper, based on 
the U.S. homeowners' credit report information, finds that U.S. households borrow 25 cents on every dollar of additional home equity value in 1997. In this section, we recalibrate the value of $b^{f}$ by referring to the household and non-profit organization (HNO) balance sheet data from Flow of Funds data set. We calculate the ratios of HNO's total liability (except mortgage) to HNO's corporate equities from 1951Q3-1992Q4, the average value is 0.4. We then set $b^{f}=0.4$. Column 1 in Figure A6 plots the transitional dynamics of key aggregate variables after financial liberalization. The two-way pattern is very similar to the one in Figure 6, indicating that our model's key predictions are not sensitive to the value of $b^{f}$.

For the parameter $\xi^{f}$, we also conduct sensitivity analysis by setting $\xi^{f}$ to a wide range of values such as $\{0.2,0.4,0.8\}$. The columns $2-4$ in Figure A6 report the implied two-way capital flows. They are broadly similar to those shown in Figure 6.

We also conducted the same sensitivity analysis for $b^{h}$ and $\xi^{h}$ for the home country. In particular, we set the values of $b^{h}$ and $\xi^{h}$ to be $1 / 4$ of their counterparts in U.S., consequently, Column 5-6 in Figure A6 shows that our model still predicts similar pattern of two-way capital flows.

Also, in our benchmark calibration, the mean of the idiosyncratic shock to investment efficiency is calibrated to match some U.S. moments. Now we simply normalize it to 1 . Column 7 in Figure A6 shows that the results do not change significantly.

\section{D.2 Alternative Process of Liberalization}

In the benchmark model, we assume that the financial market is gradually opened. One may wonder how much of the gradual divergence of the two-way capital flows shown in Figure 6 is driven by this assumption. Here we assume that the transaction costs of international capital flows immediately jump to their steady-state values after financial liberalization. Column 8 in Figure A6 shows that China's financial capital (bonds) outflows still exhibit a gradual transition pattern but the length of transition is shorter than before, while FDI inflows no longer exhibit the gradual pattern but jumps right onto the long-run path in the first year. However, as the magnitude of financial capital outflows dominates FDI inflows, the net foreign asset position still shows a gradual pattern. 

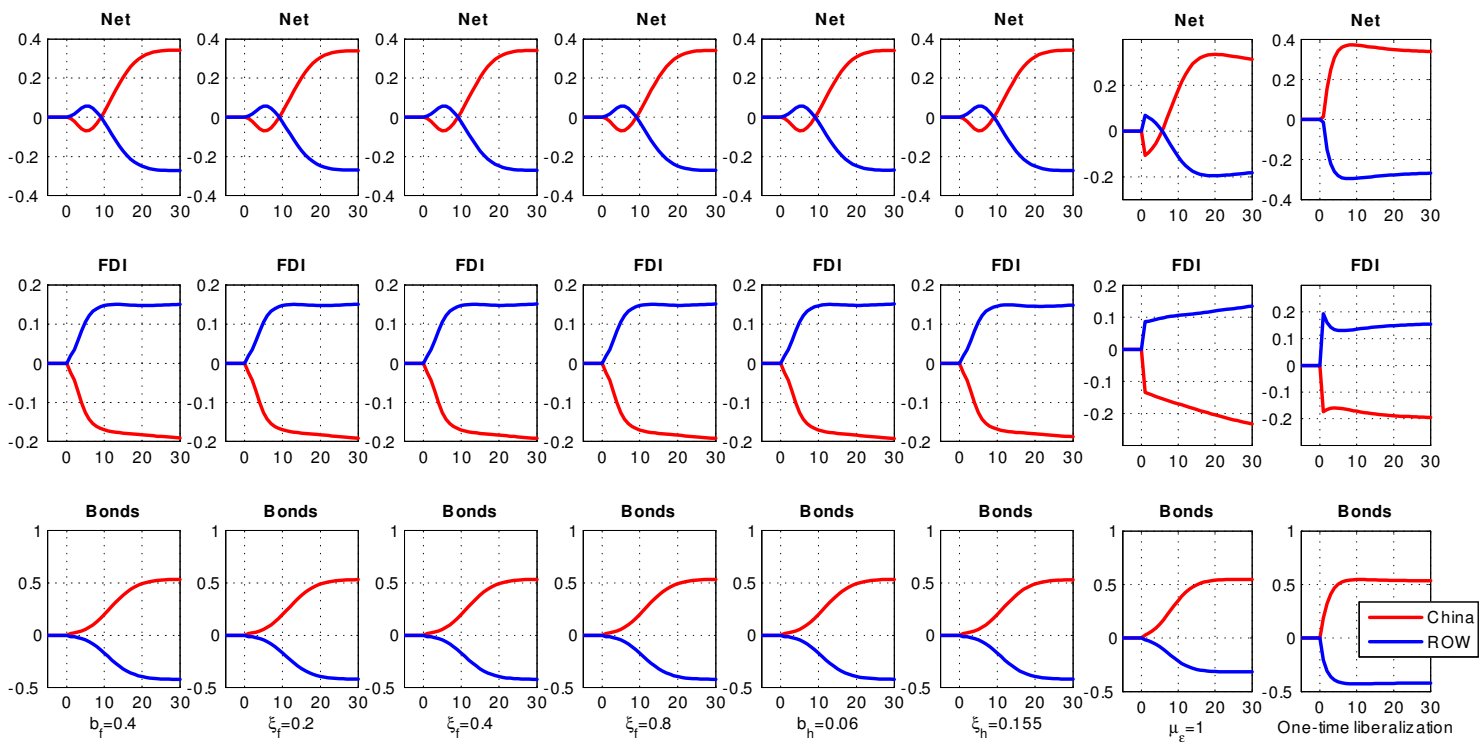

Figure A6. Two-way Patterns for Different Sensitivity Analysis.

[Note. Column 1: The parameter $b^{f}$ is fixed at 0.4. Columns 2-4: The parameter $\xi^{f}$ is fixed at $\{0.2,0.4,0.8\}$ consequently. Column 5-6: The foreign country take the same values of $\left\{b^{f}, \xi^{f}\right\}$ as those in the benchmark case. For the home country, the parameters $\left\{b^{h}, \xi^{h}\right\}$ are set to be $1 / 4$ of those in U.S., consequently. Column 7 : The parameter $\mu_{\varepsilon}$ is set to be 1 . In columns 1-7, for those parameters in the set $\Theta_{1}$, we choose the same values as those in Table 3. For those parameters in sets $\Theta_{2}$ and $\Theta_{3}$ calibrated by matching the data moments, we conduct the same calibration procedure in the benchmark case. Column 8: The financial liberalization is set to reach the steady state level immediately in period 1, i.e., the persistence parameters $\rho_{s}$ and $\rho_{k}$ are set to be zero. Other deep parameters have the same values as in Table 3.] 